\title{
THz spectroscopy and first ISM detection of excited torsional states of ${ }^{13} \mathrm{C}$-methyl formate ${ }^{\star}$
}

\author{
I. Haykal ${ }^{1}$, M. Carvajal ${ }^{2}$, B. Tercero ${ }^{3}$, I. Kleiner ${ }^{4}$, A. López ${ }^{3}$, J. Cernicharo ${ }^{3}$, R. A. Motiyenko ${ }^{1}$, T. R. Huet ${ }^{1}$, \\ J. C. Guillemin ${ }^{5}$, and L. Margulès ${ }^{1}$ \\ ${ }^{1}$ Laboratoire de Physique des Lasers, Atomes, et Molécules, UMR CNRS 8523, Université Lille I, \\ 59655 Villeneuve d'Ascq Cedex, France \\ e-mail: laurent.margules@univ-lille1.fr \\ 2 Departamento de Física Aplicada Unidad Asociada CSIC, Facultad de Ciencias Experimentales, Universidad de Huelva, \\ 21071 Huelva, Spain \\ 3 Centro de Astrobiología (CSIC-INTA), Department of Astrophysics. Ctra de Ajalvir, 28850 Torrejón de Ardoz, Madrid, Spain \\ ${ }^{4}$ Laboratoire Interuniversitaire des Systèmes Atmosphériques, UMR CNRS/IPSL 7583, Université Paris 7 et Université Paris Est, \\ 61 Av. Charles de Gaulle, 94010 Créteil Cedex, France \\ 5 Institut des Sciences Chimique de Rennes, École Nationale Supérieure de Chimie de Rennes, CNRS, UMR 6226, Allée de Beaulieu, \\ CS 50837, 35708 Rennes Cedex 7, France
}

Received 29 October 2013 / Accepted 24 April 2014

\begin{abstract}
Context. An astronomical survey of interstellar molecular clouds needs a previous analysis of the spectra in the microwave and sub-mm energy range of organic molecules to be able to identify them. We obtained very accurate spectroscopic constants in a comprehensive laboratory analysis of rotational spectra. These constants can be used to predict the transitions frequencies very precisely that were not measured in the laboratory.

Aims. We present the experimental study and its theoretical analysis for two ${ }^{13} \mathrm{C}$-methyl formate isotopologues to detect these two isotopologues for the first time in their excited torsional states, which lie at $130 \mathrm{~cm}^{-1}(200 \mathrm{~K})$ in Orion-KL.

Methods. New spectra of $\mathrm{HCOO}^{13} \mathrm{CH}_{3}\left({ }^{13} \mathrm{C}_{2}\right)$ methyl formate were recorded with the mm- and submm-wave spectrometer in Lille from 50 to $940 \mathrm{GHz}$. A global fit for $v_{t}=0$ and 1 was accomplished with the BELGI program to reproduce the experimental spectra with greater accuracy.

Results. We analysed 5728 and 2881 new lines for $v_{t}=0$ and 1 for $\mathrm{HCOO}^{13} \mathrm{CH}_{3}$. These new lines were globally fitted with 846 previously published lines for $v_{t}=0$. In consequence, 52 parameters of the RAM Hamiltonian were accurately determined and the value of the barrier height $\left(V_{3}=369.93168(395) \mathrm{cm}^{-1}\right)$ was improved. We report the detection of the first excited torsional states $\left(v_{t}=1\right)$ in Orion-KL for the ${ }^{13} \mathrm{C}_{2}$ and ${ }^{13} \mathrm{C}_{1}$ methyl formate based on the present analysis and previously published data. We provide column densities, isotopic abundances, and vibrational temperatures for these species.

Conclusions. Following this work, accurate prediction can be provided. This permits detecting 135 features of the first excited torsional states of ${ }^{13} \mathrm{C}$-methyl formate isotopologues in Orion-KL in the 80-280 GHz frequency range, without missing lines.
\end{abstract}

Key words. line: identification - astronomical databases: miscellaneous - ISM: molecules - submillimeter: ISM - astrochemistry ISM: individual objects: Orion KL

\section{Introduction}

Methyl formate is one of the most abundant complex organic molecules in the interstellar medium (ISM). It was identified in different sources since 1975 (Brown et al. 1975; Churchwell et al. 1975); nearly one thousand lines were detected in the ground-torsional state $v_{t}=0$. Its abundance is particularly high in Orion-KL: it was detected up to $900 \mathrm{GHz}$ (Comito et al. 2005) far from the maximum of absorption situated around $300 \mathrm{GHz}$; some lines from the first (Kobayashi et al. 2007), and more recently, lines from the second torsional state were detected (Takano et al. 2012). The abundance is also fairly high in W51e2, where lines from methyl formate in its first torsional states were found (Demyk et al. 2008). Molecules in the ISM can be used to

* Full Table A.1 and the IRAM spectra as FITS files are only available at the CDS via anonymous ftp to cdsarc.u-strasbg. fr $(130.79 .128 .5)$ or via

http://cdsarc.u-strasbg.fr/viz-bin/qcat?]/A+A/568/A58 probe the physical conditions of sources, as illustrated recently by Favre et al. $(2011,2014)$ using methyl formate to probe the temperature structure and spatial distribution of this species in Orion-KL; depending on the molecular species, the distribution of the molecular gas can be different in this source because of its complexity (which is a result of massive star formation processes) different cloud components coexist there. Organic saturated O-rich molecules such as methyl formate generally trace the compact ridge component (for a description of the different cloud components of Orion-KL see e.g. Blake et al. 1987; Schilke et al. 2001; Persson et al. 2007; Tercero et al. 2010, 2011; Neill et al. 2013).

Around 180 molecules have been detected in the ISM or circumstellar shells, but in high mass-forming regions such as Orion-KL, 30\% of the lines remain unidentified (Esplugues et al. 2013a; Tercero et al. 2010). Its important to identify all the lines from the most abundant species. These molecules are often called "weeds", and methyl formate is one of them. 
Identifying them is necessary in order to discover new species in the ISM without ambiguity. As shown recently by Tercero et al. (2013), the detection of methyl acetate $\left(\mathrm{CH}_{3} \mathrm{COOCH}_{3}\right)$ and the gauche conformer of ethyl formate $\left(\mathrm{g}-\mathrm{CH}_{3} \mathrm{CH}_{2} \mathrm{OCOH}\right)$ was only possible with the assignment of 4400 lines coming from several isotopologues and vibrational levels of different weeds: $\mathrm{CH}_{3} \mathrm{CH}_{2} \mathrm{CN}, \mathrm{CH}_{2} \mathrm{CHCN}, \mathrm{HCOOCH}_{3}$, and $\mathrm{NH}_{2} \mathrm{CHO}$.

Most of the times, accurate spectroscopic data in the millimeter and submillimeter-wave domain are not available for the isotopologues and vibrational levels. While the normal species of methyl formate were extensively studied (Ilyushin et al. 2009, and references therein) of only the two commercially available isotopologues $\mathrm{H}^{13} \mathrm{COOCH}_{3}$ (Maeda et al. 2008a,b) and $\mathrm{DCOOCH}_{3}$ (Oesterling et al. 1995) were studied in the millimeter-wave region. Therefore we decided to investigate all the mono-isotopic species of methyl formate in the submillimeter-wave domain a few years ago. For each of them, this permits generating a new accurate prediction and allows detecting the ${ }^{13} \mathrm{C}$ species (Willaert et al. 2006; Carvajal et al. 2007, 2009, 2010), $\mathrm{DCOOCH}_{3}$ (Margulès et al. 2010), ${ }^{18} \mathrm{O}$ species (Tercero et al. 2012) in Orion-KL and recently $\mathrm{HCOOCH}_{2} \mathrm{D}$ (Coudert et al. 2013). This confirms the assumption that most of the U-lines come from known molecules. The lines detected for the ${ }^{18} \mathrm{O}$ species gave us the idea that it might also be possible to find lines related to the first excited torsional states that lie at $130 \mathrm{~cm}^{-1}(200 \mathrm{~K})$ of the most abundant isotopologues ${ }^{13} \mathrm{C}$.

Our motivations for studying of the first excited torsional state of $\mathrm{HCOO}^{13} \mathrm{CH}_{3}$ is also linked to a spectroscopic interest. Methyl formate, like other complex molecules, exhibits largeamplitude motion: torsion of the methyl group related to the rest of the molecules. A specific code that takes into account the interaction of the torsion and the overall rotation of the molecule is needed. Most of the codes were developed to treat data in the centimeter not in millimeter-wave domain. Recent efforts from different theoretical groups were recently make to improve the codes to reproduce the experimental accuracies with high quantum numbers that are reached at submillimeter frequencies. As shown for the normal species (Ilyushin et al. 2009) and the ${ }^{13} \mathrm{C}_{1}$ species (Carvajal et al. 2010), the global treatment of the ground- and first torsional states permits removing the high correlation between torsional parameters. This improves the quality of the fit and finally the accuracy of the predictions for the two states.

These works permit the first detection of the excited torsional state of the two ${ }^{13} \mathrm{C}$-methyl formate isotopologues. As in Carvajal et al. (2009), we publish the spectroscopic work about $\mathrm{HCOO}^{13} \mathrm{CH}_{3}$ and the detection of the two ${ }^{13} \mathrm{C}$ isotopologues in Orion together. In the previous paper about ${ }^{13} \mathrm{C}_{2}$ (Carvajal et al. 2009), our measurements were limited to $660 \mathrm{GHz}$ for the ground-torsional states. To provide an accurate prediction of this state in the ALMA range, we also reinvestigated this state up to $940 \mathrm{GHz}$.

\section{Experiments}

\subsection{Synthesis of the methyl formate isotopologue $\mathrm{HCOO}^{13} \mathrm{CH}_{3}$}

The details about synthesis and identification by NMR spectroscopy were described in Carvajal et al. (2009).

\subsection{Lille - submillimeter spectra}

The millimeter- and submillimeter-wave spectra were recorded using the Lille spectrometer that is based on solid-state sources
(Motiyenko et al. 2010; Haykal et al. 2013a). The sample pressure was in the range $20-30 \times 10^{-6}$ bars. Spectra were recorded at room temperature $(T=294 \mathrm{~K})$ in the $150-210,225-315$, 400-500, 500-630, and 780-940 GHz regions with frequency steps of $30,36,48,54$, and $76 \mathrm{kHz}$ and an acquisition time of $35 \mathrm{~ms}$ per point. Absorption signals were detected either by a Schottky diodes detector (Virginia Diodes Inc.) below $315 \mathrm{GHz}$ or by an InSb liquid He-cooled bolometer (QMC Instruments Ltd.) above $400 \mathrm{GHz}$, and were processed on a computer. The absolute accuracy of the line-centre frequency is estimated to be better than $30 \mathrm{kHz}(50 \mathrm{kHz}$ above $700 \mathrm{GHz})$ for isolated lines and can be as low as $100 \mathrm{kHz}(150 \mathrm{kHz}$ above $700 \mathrm{GHz})$ for blended or very weak lines.

\section{Assignments and fit of the $\mathrm{HCOO}^{13} \mathrm{CH}_{3}$ spectrum}

The theoretical model and the so-called RAM method (rho-axis method) used for the present spectral analyses and fits of the ground- and first torsional-excited states of $\mathrm{HCOO}^{13} \mathrm{CH}_{3}$ species have also been used previously for a number of molecules that contain an internal methyl rotor (see for example Ilyushin et al. 2003, 2008) and in particular for the normal species of the cismethyl formate (Carvajal et al. 2007; Ilyushin et al. 2009), the two ${ }^{13} \mathrm{C}$ species (Carvajal et al. 2009, 2010), for $\mathrm{DCOOCH}_{3}$ (Margulès et al. 2010), and for ${ }^{18} \mathrm{O}$ species (Tercero et al. 2012). The RAM Hamiltonian we used is based on previous works (Kirtman 1962; Lees \& Baker 1968; Herbst et al. 1984). Because this method has been presented in great detail in the literature (Lin \& Swalen 1959; Hougen et al. 1994; Kleiner 2010), we do not describe it here. The principal advantage of the RAM general approach used in our code BELGI, which is publicly available ${ }^{1}$, is its general approach that simultaneously takes into account the A- and E-symmetry states in our fit. All the torsional levels up to a truncation limit of $v_{t}=8$ are carefully tested and the interactions within the rotation-torsion energy levels are also included in the rotation-torsion Hamiltonian matrix elements (Kleiner et al. 1996). The various rotational, torsional, and coupling terms between rotation and torsion that we used for the fit of the $\mathrm{HCOO}^{13} \mathrm{CH}_{3}$ species were defined previously for the normal methyl formate species (Carvajal et al. 2007). The labelling scheme of the energy levels and transitions used for methyl formate was also described in the same reference, as was the connection with the more traditional $J_{K_{a}, K_{c}}$ labelling.

We started with the assignment of the ground state. Predictions were provided by the BELGI program based on the set of 27 parameters previously determined in Carvajal et al. (2009). In this reference, only 658 lines were assigned from 150 to $700 \mathrm{GHz}$. Our new spectrometer has a wider coverage range than that used in 2009. Based on the previous work, we easily assigned the spectra up to $J=63$ and $K_{a}=34$ in the range $75-630 \mathrm{GHz}$. In the highest frequency range of the $\mathrm{mm}$ and submm- wave spectrometer (700-940 GHz), the assignment was tentative because of the shift of the predicted lines from the experimental lines. The upper limit in frequency of the 936 previously fitted lines was $700 \mathrm{GHz}$. As a result, we assigned for the ground-state 5728 lines up to $J=60$ and $K_{a}=35$ from 50 to $940 \mathrm{GHz}$. Next, we started up again, but simultaneously including data of states $v_{t}=0$ and $v_{t}=1$. The fit was carried out in

1 The source code for the fit, an example of input data file, and a readme file are available at the web site (http://www.ifpan.edu.

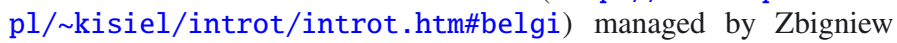
Kisiel. Extended versions of the code made to fit transitions with higher $J$ and $K$ are also available from the authors (I. Kleiner and M.C.). 


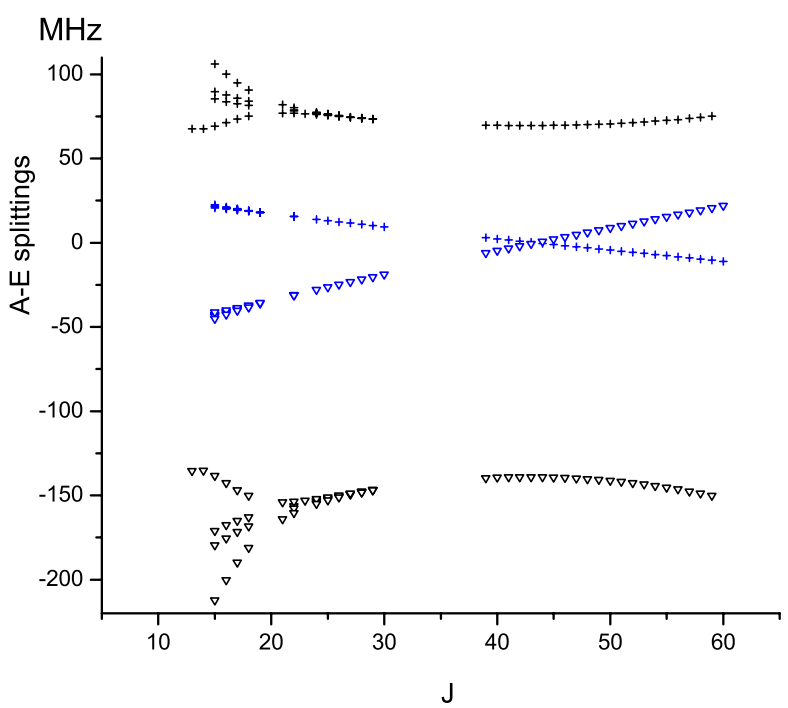

Fig. 1. A-E splitting of selected branches ( $\mathrm{R}$ branches for $K_{a}=0 ; 1$ in blue and 1;2 in black) for $v_{t}=1$. The $x$-axis represents the situation without perturbation. The A transitions ( $\nabla$ signs) are twice as far as the E transitions (+ signs). For $K_{a}=0 ; 1$ the A-E splitting changes sign at $J=44$ (Ilyushin et al. 2009).

these two steps to avoid any possible misassignments. The improvement of the fit is then based on the variety and richness of the data set, and the addition of lines belonging to $v_{t}=1$ is crucial. The analysis of the first excited torsional state was challenging because of a larger splitting of the A and $\mathrm{E}$ component by the tunnelling effect. In a recent work by Tudorie et al. (2012) the band origins $\left(E_{\mathrm{A}}=132.4303 \mathrm{~cm}^{-1}\right.$ and $\left.E_{\mathrm{E}}=131.8445 \mathrm{~cm}^{-1}\right)$ for $v_{t}=1$ of the parent molecule were precisely determined by a combination of microwave, mm-wave, submm-wave, and far infrared data. The value of height of the barrier was as much improved and $V_{3}$ was determined to be equal to 370.7398 (58) $\mathrm{cm}^{-1}$. In this work, for $\mathrm{HCOO}^{13} \mathrm{CH}_{3}$, the first torsional excited substates are predicted to be $E_{\mathrm{A}}=131.0565 \mathrm{~cm}^{-1}$ and $E_{\mathrm{E}}=130.4856 \mathrm{~cm}^{-1}$. We estimated the rotational parameters using the same difference of the ground- and the first-torsional excited states rotational parameters of the ${ }^{12} \mathrm{C}$ species. In the assignment procedure, the a-type transitions with A symmetry of R-branches were first analysed, in particular, the most intense lines with $K_{a}=0$ and 1 .

Methyl formate is a fairly asymmetric near-prolate top for which the dipole moment is non-zero along the a and b principle axis. For the parent specie, $\mu_{a}$ and $\mu_{b}$ were measured by Margulès et al. (2010) and their values are 1.648(8) and $0.706(12) \mathrm{D}$. We tracked these transitions based on the intensity criterion. Next we assigned the E type of transitions with the same benchmarks as those adopted for the A type of transitions. For $K_{a}$ the splitting between the A transitions, as well as between the E transitions, decreases with the increase of the $J$ quantum number. Four $\mu_{a}$ and $\mu_{b}$ rotational transitions with the same symmetry (A or E) become blended at $J=24$. Furthermore, in the $\mathrm{mm}$-wave ranges the splitting between the $\mathrm{A}$ and $\mathrm{E}$ transitions decreases with the increase of $J$ and at a specific value of $J$ in the submm-wave ranges this splitting changes sign (Fig. 1). Following this behaviour of the A and E type of transition for $K_{a}=0$ and 1 , we assigned them up to $J=50$ at $\sim 520 \mathrm{GHz}$. We fitted these for $v_{t}=1$ with the ERHAM (Groner 1997, 2012) program. The predictions based on this first fit were accurate enough to continue and to search for higher quantum number lines. We collected $800 \mathrm{~A}$ lines and $596 \mathrm{E}$ lines with $K_{a, \max }=19$ and 11 up to $J=50$ for the A and E lines. ERHAM ${ }^{2}$ treats each torsional state separately, and to proceed with the global analysis of $v_{t}=0$ and 1 , we used BELGI. The final data set with the upper limits of the quantum numbers and the experimental uncertainties are summarized in Table 1 . The 6574 lines belonging to $v_{t}=0$ and 2881 lines belonging to $v_{t}=1$ were fitted with rootmean-square deviations of 38.3 and $41.9 \mathrm{kHz}$. The fit of the total of 9455 lines for $v_{t}=0$ and 1 of $\mathrm{A}$ and $\mathrm{E}$ symmetries resulted in the determination of 52 parameters of the RAM Hamiltonian. Table 3 presents the values of the set of 52 newly determined parameters. In this table we also provide a comparison with the previous work. Principally, we note a striking change in the value of the barrier height. The value of the parameter $V_{3}$ changed from 407.1549 (147) to $369.93168(395) \mathrm{cm}^{-1}$.

The reason for this is the fact that this parameter is an effective value. In the previous fit (Carvajal et al. 2009), the data set of lines concerned only the $v_{t}=0$ state and, therefore, neither the second-order parameter $\left(V_{6}\right)$ of the torsional potential function nor the kinetic parameter $F$ could be determined. Then, $F$ was fixed to a relatively high value estimated by ab initio methods, and in the fitting procedure, the effective value of $V_{3}$ absorbed the error of $F$ and contained the contribution of $V_{6}$ :

$V(\gamma)=\frac{V_{3}}{2} \times(1-\cos 3 \gamma)+\frac{V_{6}}{2} \times(1-\cos 6 \gamma)+\ldots$

The new combination of data from $v_{t}=0$ and 1 improved the quality of the fit and allowed determining of 25 new parameters, particularly $F$ and $V_{6}$.

\section{Line strengths}

The intensity calculations for the two ${ }^{13} \mathrm{C}$ species of methyl formate were performed using the same method described in Hougen et al. (1994) and Ilyushin et al. (2008), that was applied for the normal species by Carvajal et al. (2007), the ${ }^{13} \mathrm{C}$ species (Carvajal et al. 2009, 2010), DCOOCH $_{3}$ (Margulès et al. 2010), and ${ }^{18} \mathrm{O}$ species (Tercero et al. 2012). For this reason we do not repeat it here. The line strength calculation for the ${ }^{13} \mathrm{C}$ species was performed using the same value for the dipole moment as for the parent methyl formate (Margulès et al. 2010). This assumption was made because the angle between the internal axis of the methyl top and the principal $a$-axis does not change much upon substitution (see the $<(i, a)$ angle values in Table 3 ). All other structural parameters such as the angle between RAM and PAM axes $\left(\theta_{\text {RAM }}\right)$ and the $\rho$ parameter do not change much upon substitution (see Table 3 ). Because the changes in the structure in the various isotopomers are not important, we assumed that the dipole moment does not change considerably from one species to another. The dipole moment components of $\mathrm{H}^{13} \mathrm{COOCH}_{3}$ (Carvajal et al. 2010) and $\mathrm{HCOO}^{13} \mathrm{CH}_{3}$ in RAM axis system that we used for the intensity calculations are $\mu_{a}^{\mathrm{RAM}}=1.792 \mathrm{D}$; $\mu_{b}^{\mathrm{RAM}}=-0.044 \mathrm{D}$ and $\mu_{a}^{\mathrm{RAM}}=1.793 \mathrm{D} ; \mu_{b}^{\mathrm{RAM}}=-0.022 \mathrm{D}$, respectively. We provide Table A.1, which is part of the supplementary Table $\mathrm{S}$ (available on CDS). It contains all included lines from our fit for the $\mathrm{HCOO}^{13} \mathrm{CH}_{3}$ methyl formate species. They show the line assignments, the observed frequencies with measurement uncertainty (in parenthesis), the computed frequencies, observed-calculated values, the line strength, and the lower-state energy relative to the $J=K=0$ A-species level taken as zero-energy level. The prediction line-list of all transitions in $v_{t}=0$ and 1 will be transmitted to the SPLATALOG and CDMS database (available at www . splatalogue .net).

\footnotetext{
2 http://www.ifpan.edu.pl/ kisiel/introt/introt.htm\# erham
} 
Table 1. Root-mean-square (rms) deviations from the global fit ${ }^{a}$ of transitions involving $v_{t}=0$ and $v_{t}=1$ torsional energy levels of ${ }^{13} \mathrm{C}_{2}$-methyl formate $\left(\mathrm{HCOO}^{13} \mathrm{CH}_{3}\right)$.

\begin{tabular}{|c|c|c|c|c|c|}
\hline \multicolumn{4}{|c|}{$\begin{array}{l}\text { Number of parameters } \\
\text { Number of lines } \\
\text { rms of the } 6574 \mathrm{MW} v_{t}=0-0 \text { lines } \\
\text { rms of the } 2881 \mathrm{MW} v_{t}=1-1 \text { lines } \\
\text { rms of the } 5184 \text { A symmetry lines } \\
\text { rms of the } 4271 \text { E symmetry lines }\end{array}$} & \multicolumn{2}{|c|}{$\begin{array}{c}52 \\
9455 \\
0.0383 \mathrm{MHz} \\
0.0419 \mathrm{MHz} \\
0.0429 \mathrm{MHz} \\
0.0349 \mathrm{MHz} \\
\end{array}$} \\
\hline Source $^{b}$ & $\operatorname{Range}^{c}(\mathrm{GHz})$ & $v_{t}, J_{\max }, K_{\max }{ }^{d}$ & Number of lines ${ }^{e}$ & Uncertainties $^{f}(\mathrm{MHz})$ & $\mathrm{rms}^{g}(\mathrm{MHz})$ \\
\hline AA09 & $4-20$ & $0,7,3$ & 27 & 0.005 & 0.0056 \\
\hline $\begin{array}{l}\text { AA09 } \\
\text { NEW } \\
\text { NEW } \\
\text { AA09 } \\
\text { NEW } \\
\text { NEW }\end{array}$ & $\begin{array}{c}150-700^{j} \\
50-940^{k} \\
50-940^{k} \\
150-700^{j} \\
50-940^{k} \\
50-940^{k}\end{array}$ & $\begin{array}{l}0,63,35 \\
0,60,35 \\
1,60,26 \\
0,52,27 \\
0,52,35 \\
1,58,26\end{array}$ & $\begin{array}{c}607 \\
4864 \\
1731 \\
2 \\
577 \\
814\end{array}$ & $\begin{array}{l}0.030 \\
0.030 \\
0.030 \\
0.050 \\
0.050 \\
0.050\end{array}$ & 0.0252 \\
\hline $\begin{array}{l}\text { AA09 } \\
\text { NEW } \\
\text { NEW }\end{array}$ & $\begin{array}{c}8-700^{j} \\
50-940^{k} \\
50-940^{k}\end{array}$ & $\begin{array}{l}0,58,29 \\
0,55,33 \\
1,57,26\end{array}$ & $\begin{array}{c}43 \\
170 \\
203 \\
\end{array}$ & $\begin{array}{l}0.100^{h} \\
0.100^{i} \\
0.100^{i}\end{array}$ & 0.0644 \\
\hline $\begin{array}{l}\text { AA09 } \\
\text { NEW } \\
\text { NEW } \\
\text { AA09 } \\
\text { NEW } \\
\text { NEW }\end{array}$ & $\begin{array}{c}8-700^{j} \\
50-940^{k} \\
50-940^{k} \\
8-700^{j} \\
50-940^{k} \\
50-940^{k}\end{array}$ & $\begin{array}{l}0,33,11 \\
0,54,33 \\
1,55,24 \\
0,58,25 \\
0,55,31 \\
1,55,20\end{array}$ & $\begin{array}{c}122 \\
49 \\
68 \\
45 \\
68 \\
65\end{array}$ & $\begin{array}{c}0.150^{h} \\
0.150^{i} \\
0.150^{i} \\
0.200^{h} \\
0.200^{i} \\
0.200^{i}\end{array}$ & 0.1345 \\
\hline
\end{tabular}

Notes. ${ }^{(a)}$ Parameter values are given in Table 2. The complete list of observed minus calculated residuals of $v_{t}=0$ lines are given in the supplementary Table A.1. ${ }^{(b)}$ Sources of data: AA09 stands for Carvajal et al. (2009) and NEW data come from the present work. The spectroscopic instruments are described in Sect. 2.2. ${ }^{(c)}$ Spectral range of the measurements. ${ }^{(d)}$ Torsional state $v_{t}$, maximum $J$ and $K_{a}$ for each group of measurements. ${ }^{(e)}$ Number of MW lines in each uncertainty group. ${ }^{(f)}$ Uncertainty in MHz used in the fit. ${ }^{(g)}$ Root-mean-square deviation in MHz for each group. ${ }^{(h)}$ The details of the accuracy of spectral measurements are given in Carvajal et al. (2009). ${ }^{(i)}$ The accuracy of spectral measurements for the Lille spectrometer is about $0.030 \mathrm{MHz}$ for isolated lines but some lines are either blended or present a poor S/N ratio and therefore their measurement accuracy is taken as either $0.100 \mathrm{MHz}, 0.150 \mathrm{MHz}$ or $0.200 \mathrm{MHz}$ according to the broadening of the experimental line. (j) The spectrometer spectral ranges for these measurements are $8-80 \mathrm{GHz}, 150-245 \mathrm{GHz}, 320-350 \mathrm{GHz}, 510-525 \mathrm{GHz}$, and $580-661 \mathrm{GHz}$ (for more details, see Carvajal et al. 2009). ${ }^{(k)}$ The spectrometer spectral ranges for the measurements of present work are: $50-100 \mathrm{GHz}$ and $150-940 \mathrm{GHz}$, using a multiplication chain of solid state sources, and 100-150 GHz, using a backward wave oscillator.

\section{Detection of ${ }^{13} \mathrm{C}-\mathrm{HCOOCH}{ }_{3} v_{t}=1$ in Orion $\mathrm{KL}$}

In this section we use the notation ${ }^{13} \mathrm{C}-\mathrm{HCOOCH}_{3}$ when we refer to the two isotopologues. Following the procedure of our previous papers, we searched for the present species in the molecular line survey of Orion KL performed with the IRAM $30 \mathrm{~m}$ telescope. We detected both ${ }^{13} \mathrm{C}$ isotopologues of methyl formate in their first vibrationally excited state. In Sect. 5.1 we summarize the observations, data reduction, and overall results of this survey. We present the new detection in Sect. 5.2. In Sect. 5.3 we explain the assumed model and the excitation and radiative transfer calculations for vibrationally excited ${ }^{13} \mathrm{C}$ and ${ }^{12} \mathrm{C}$ methyl formate. We also compute our obtained ${ }^{12} \mathrm{C} /{ }^{13} \mathrm{C}$ ratio and the vibrational temperature for ${ }^{13} \mathrm{C}-\mathrm{HCOOCH}_{3} v_{t}=1$.

\subsection{Observations, data reduction, and overall results}

The molecular line survey towards Orion KL-IRc2 $(\alpha(\mathbf{J} 2000)=$ $\left.5^{\mathrm{h}} 35^{\mathrm{m}} 14.5^{\mathrm{s}}, \delta(\mathrm{J} 2000)=-5^{\circ} 22^{\prime} 30.0^{\prime \prime}\right)$ was performed between September 2004 and January 2007 in five observing sessions with the IRAM $30 \mathrm{~m}$ telescope. All frequencies allowed by the A, B, C, and D receivers were covered (80-115.5, 130-178, and $197-281 \mathrm{GHz}$ ) with a spectral resolution of $1-1.25 \mathrm{MHz}$. System temperatures, image side-band rejections, and halfpower beam widths were in the ranges $100-800 \mathrm{~K}, 27-13 \mathrm{~dB}$, and 29-9", from 80 to $281 \mathrm{GHz}$. The observations were performed in the balanced wobbler-switching mode. Pointing and focus were checked every $1-2 \mathrm{~h}$ on nearby quasars. The inten- sity scale was calibrated with two absorbers at different temperatures using the ATM package (Cernicharo 1985; Pardo et al. 2001).

The data were processed using the GILDAS software ${ }^{3}$. The data reduction consisted of removing lines from the image sideband and fitting and removing baselines. We observed each frequency setting twice, with the second one shifted in frequency by $20 \mathrm{MHz}$. This allowed us to remove lines from the image sideband down to a level of $30 \mathrm{~dB}$ (this means that lines in the image side-band of $30 \mathrm{~K}$ will contribute with less than $0.03 \mathrm{~K}$ to the final reduced spectrum). Figures are shown in units of main-beam antenna temperature, $T_{\mathrm{MB}}=T_{\mathrm{A}}^{\star} / \eta_{\mathrm{MB}}$, where $\eta_{\mathrm{MB}}$ is the mainbeam efficiency ranged from 0.82 to 0.48 from the lowest to the highest frequencies. For a detailed description of the observations and data reduction procedures see Tercero et al. (2010).

Up to date, we performed a deep analysis of the data (15 papers have been already published): identifying more than 15000 spectral features (Tercero et al. 2010; Tercero 2012), detecting new molecules in space $\left(\mathrm{CH}_{3} \mathrm{COOCH}_{3}\right.$ and $\mathrm{g}-\mathrm{CH}_{3} \mathrm{CH}_{2} \mathrm{OCOH}$ in Tercero et al. 2013; $\mathrm{NH}_{3} \mathrm{D}^{+}$in Cernicharo et al. 2013; $\mathrm{CH}_{3} \mathrm{CH}_{2} \mathrm{SH}$ in Kolesniková et al. 2014; also tentative detections of $\mathrm{c}^{-\mathrm{C}_{6}} \mathrm{H}_{5} \mathrm{O}$ in Kolesniková et al. 2013 and upper limit calculations for the column density of non detected molecules - cis- $\mathrm{CH}_{2} \mathrm{CHCH}_{2} \mathrm{CN}$ and cis- $\mathrm{CH}_{2} \mathrm{CHCH}_{2} \mathrm{NC}-$ in Haykal et al. 2013b) and several new isotopologues and

3 http://www.iram.fr/IRAMFR/GILDAS 
I. Haykal et al.: THz spectroscopy and ISM detection of $v_{t}=1$ of ${ }^{13} \mathrm{C}$-methyl formate

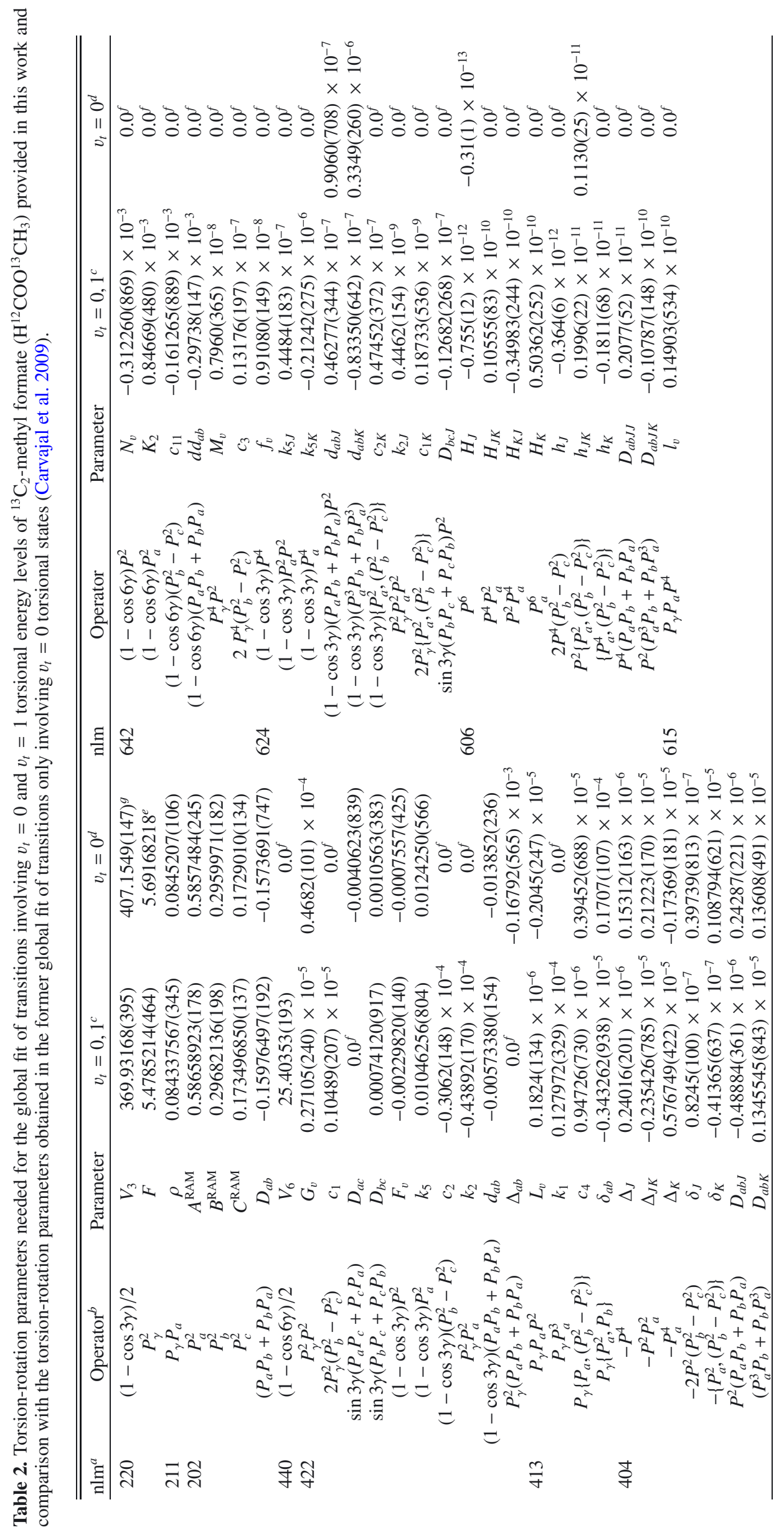

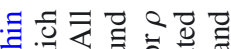

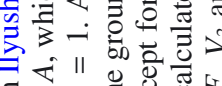

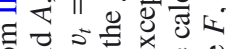

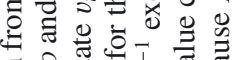

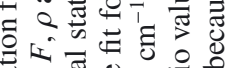

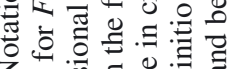

$z$ 要

今.

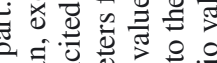

.

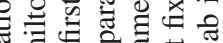

흥

o

of

혼 울

응

을

证

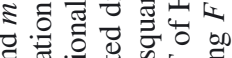

政. 응

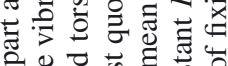

2.

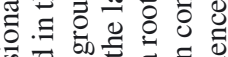

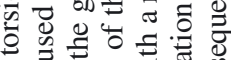

응

응

可

응

嗐

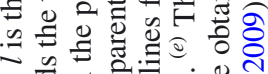

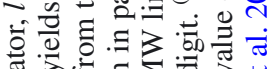

के

응 亮

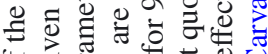

的政.

害 石

进

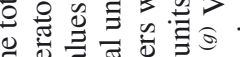

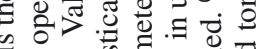

诃.

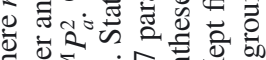

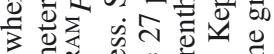

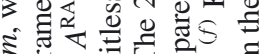

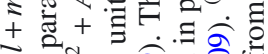

"I 0.00

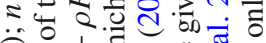

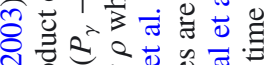

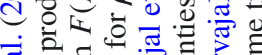

政

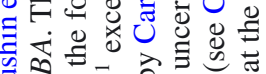

$5+.500$

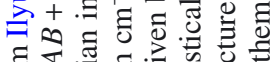

자.

迸 II

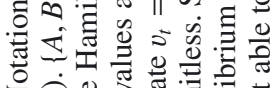

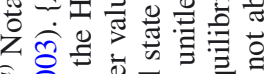

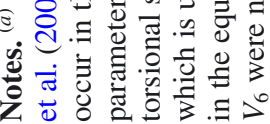

A58, page 5 of 16 
Table 3. Rotational constants in the principal axis system (PAM), angles between the principal axis and the methyl top axis, and internal rotation parameters upon isotopic substitution.

\begin{tabular}{cccc}
\hline \hline & $\begin{array}{c}\mathrm{HCOOCH}_{3}{ }^{a} \\
\text { Global fit }\left(v_{t}=0,1\right)\end{array}$ & $\begin{array}{c}\mathrm{HCOO}^{13} \mathrm{CH}_{3}{ }^{b} \\
\text { Global fit }\left(v_{t}=0\right)\end{array}$ & $\begin{array}{c}\mathrm{HCOO}^{13} \mathrm{CH}_{3}{ }^{c} \\
\text { Global fit }\left(v_{t}=0,1\right)\end{array}$ \\
\hline$A(\mathrm{MHz})$ & $19924.4249(433)$ & $19629.65(176)$ & $19707.8000(625)$ \\
$B(\mathrm{MHz})$ & $6947.9458(414)$ & $6804.42(171)$ & $6776.1833(660)$ \\
$C(\mathrm{MHz})$ & $5318.10685(450)$ & $5183.442(402)$ & $5201.30471(410)$ \\
$<(i, a)^{d}$ & 53.06 & 51.68 & $52.18(25)$ \\
$\theta_{\mathrm{RAM}^{e}}$ & $24.87951(13)$ & 23.68 & $23.89824(22)$ \\
$\rho$ & $0.08427227(25)$ & $0.0845207(106)$ & $0.084337567(345)$ \\
$F\left(\mathrm{~cm}^{-1}\right)$ & $5.497592(59)$ & $5.69168218^{f}$ & $5.4785214(464)$ \\
$V_{3}\left(\mathrm{~cm}^{-1}\right)$ & $370.7398(58)$ & $407.1549(147)$ & $369.93168(395)$ \\
$\sigma^{g}$ & 0.67 & 1.08 & 0.77 \\
$\mathrm{~N}^{o}$ of transitions & 15840 & 936 & 9455 \\
$\mathrm{~N}^{\mathrm{o}}$ of fitted parameters & 53 & 27 & 52 \\
\hline
\end{tabular}

Notes. ${ }^{(a)}$ Rotation-torsion parameters for the normal species $\mathrm{HCOOCH}_{3}$ obtained in Tudorie et al. (2012) with the RAM-axis system, after transforming the RAM values for the A, B, C rotational parameters into PAM values following the procedure described in Carvajal et al. (2007). The RAM to PAM transformation is given in Carvajal et al. (2010). ${ }^{(b)}$ Rotation-torsion parameters for ${ }^{13} \mathrm{C}_{2}$-methyl formate from Carvajal et al. (2009) transformed to the principal axis system. ${ }^{(c)}$ Rotation-torsion parameters for ${ }^{13} \mathrm{C}_{2}$-methyl formate from the present work transformed into the principal axis system. ${ }^{(d)}$ Angle in degrees between the a-principal axis and the methyl top axis $(i) .{ }^{(e)}$ The angle $\theta_{\mathrm{RAM}}$ between the $a$-principal axis and the $a$-RAM axis is given in degrees and obtained from Eq. (1) from Carvajal et al. (2007), with the parameters $A^{\mathrm{RAM}}, B^{\mathrm{RAM}}, C^{\mathrm{RAM}}$, and $D_{\text {ab }}$ of Table 2. ${ }^{(f)}$ Fixed to the ab initio value (Carvajal et al. 2009). ${ }^{(g)}$ Unitless standard deviation.

Table 4. Kinematic parameters and physical conditions of the Orion-KL spatial components.

\begin{tabular}{lllll}
\hline \hline Parameter & $\begin{array}{l}\text { Extended ridge } \\
(\mathrm{ER})\end{array}$ & $\begin{array}{l}\text { Compact ridge } \\
(\mathrm{CR})\end{array}$ & $\begin{array}{l}\text { Plateau } \\
(\mathrm{P})\end{array}$ & $\begin{array}{l}\text { Hot core } \\
(\mathrm{HC})\end{array}$ \\
\hline Source diameter (") & $\simeq 120(120)$ & $5-15(15)$ & $20-30(30)$ & $5-10(10)$ \\
Offset $\left(\right.$ from IRc2) $\left(^{\prime \prime}\right)$ & $0(0)$ & $7(7)$ & $0(0)$ & $2-3(2)$ \\
$n\left(\mathrm{H}_{2}\right)\left(\mathrm{cm}^{-3}\right)$ & $\simeq 10^{5}$ & $\simeq 10^{6}$ & $\simeq 10^{6}$ & $10^{7}-10^{8}$ \\
$T_{k}(\mathrm{~K})$ & $\simeq 60(60)$ & $80-150(110)$ & $100-150(125)$ & $150-300(225)$ \\
$\Delta v_{F W H M}\left(\mathrm{~km} \mathrm{~s}^{-1}\right)$ & $\simeq 4(4)$ & $3-5(4)$ & $\simeq 25(25)$ & $5-15(10)$ \\
$v_{\text {LSR }}\left(\mathrm{km} \mathrm{s}^{-1}\right)$ & $8-10(8)$ & $7-9(7.5)$ & $6-11(9)$ & $3-6(5.5)$ \\
\hline
\end{tabular}

Notes. Parameters compiled from different authors: Blake et al. (1987); Schilke et al. (2001); Persson et al. (2007); Tercero et al. (2010); Neill et al. (2013). The values between parenthesis are those adopted for the model of $\mathrm{HCOOCH}_{3} v_{t}=1$ and ${ }^{13} \mathrm{C}-\mathrm{HCOOCH}_{3} v_{t}=0$.

vibrationally excited states of well-known molecules in this source $\left({ }^{13} \mathrm{C}_{-} \mathrm{CH}_{3} \mathrm{CH}_{2} \mathrm{CN}\right.$ in Demyk et al. $2007 ;{ }^{13} \mathrm{C}-\mathrm{HCOOCH}_{3}$ in Carvajal et al. 2009; $\mathrm{CH}_{3} \mathrm{CH}_{2}{ }^{15} \mathrm{~N}, \mathrm{CH}_{3} \mathrm{CHDCN}$, and $\mathrm{CH}_{2} \mathrm{DCH}_{2} \mathrm{CN}$ in Margulès et al. 2009; $\mathrm{DCOOCH}_{3}$ in Margulès et al. 2010; ${ }^{18} \mathrm{O}-\mathrm{HCOOCH}_{3}$ in Tercero et al. 2012; $\mathrm{NH}_{2} \mathrm{CHO}$ $v_{12}=1$ in Motiyenko et al. 2012; $\mathrm{CH}_{3} \mathrm{CH}_{2} \mathrm{CN} v_{10}=1$ and $v_{12}=1$ in Daly et al. 2013; $\mathrm{HCOOCH}_{2} \mathrm{D}$ in Coudert et al. 2013; $\mathrm{CH}_{2} \mathrm{CHCN} v_{10}=1 \Leftrightarrow\left(v_{11}=1, v_{15}=1\right)$ in López et al. 2014), and constraining physical and chemical parameters by means of the analysis of different families of molecules (OCS, CS, $\mathrm{H}_{2} \mathrm{CS}$, $\mathrm{HCS}^{+}, \mathrm{CCS}, \mathrm{CCCS}$ species in Tercero et al. 2010; $\mathrm{SiO}$ and $\mathrm{SiS}$ species in Tercero et al. 2011; $\mathrm{CH}_{3} \mathrm{CH}_{2} \mathrm{CN}$ species in Daly et al. 2013; $\mathrm{SO}$ and $\mathrm{SO}_{2}$ species in Esplugues et al. 2013a; $\mathrm{HC}_{3} \mathrm{~N}$ and $\mathrm{HC}_{5} \mathrm{~N}$ species in Esplugues et al. 2013b; $\mathrm{CH}_{3} \mathrm{CN}$ in Bell et al. 2014; $\mathrm{CH}_{2} \mathrm{CHCN}$ species and the isocyanides in López et al. 2014). In addition and to analyze some of these results, we modelese the following molecules: $\mathrm{CH}_{3} \mathrm{SH}, \mathrm{CH}_{3} \mathrm{OH}, \mathrm{CH}_{3} \mathrm{CH}_{2} \mathrm{OH}$ in Kolesniková et al. (2014), $\mathrm{HCOOCH}_{3}$ in Margulès et al. (2010), and $\mathrm{NH}_{2} \mathrm{CHO}$ in Motiyenko et al. (2012). Nevertheless, the study of this line survey is still open and several groups are working simultaneously based on the scope of these observations ${ }^{4}$.

In agreement with numerous works of this region (see e.g. Blake et al. 1987; Schilke et al. 2001; Persson et al. 2007; Neill et al. 2013), at least four cloud components could be identified in the line profiles of our low-resolution spectral lines, which are characterized by different radial velocities and line widths

\footnotetext{
4 The data of the IRAM $30 \mathrm{~m}$ line survey of Orion KL are available in ascii format on request to $\mathrm{B}$. Tercero.
}

(Tercero et al. 2010, 2011). Each component corresponds to specific region of the cloud that overlaps in our telescope beam. Table 4 summarizes the kinematic and physical parameters of the different components in Orion-KL.

\subsection{Results}

The two ${ }^{13} \mathrm{C}$ isotopologues of $\mathrm{HCOOCH}_{3}$ in their first vibrationally excited state $\left(v_{t}=1\right)$ have been detected in Orion-KL by means of 135 spectral features (77 of them practically unblended) without missing transitions in the range $80-280 \mathrm{GHz}$. Figure 2 shows selected detected lines of the two isotopologues together with our best model (see below). The black histogram line corresponds with the observed spectra. The model of the $\mathrm{H}^{13} \mathrm{COOCH}_{3} v_{t}=1$ and $\mathrm{HCOO}^{13} \mathrm{CH}_{3} v_{t}=1$ lines is shown in red and dark blue, respectively. In all boxes unblended or slightly blended detected lines of these species are depicted. The cyan blue line represents the total model compiled from our already published work (see Sect. 5.1). In Table 5 we list all detected features in our line survey. These detections are based on an inspection of the data and the modelled synthetic spectrum of the studied species and all the species already identified in our previous papers (see above). The observed main-beam temperature and the radial velocity where obtained from the peak channel of our spectra, therefore, errors in the baselines - up to $\pm 0.15 \mathrm{~K}$ for spectra at $1.3 \mathrm{~mm}$ due to the extremely high line density (line confusion limit) - and contribution from other species might affect the $T_{\mathrm{mb}}^{\mathrm{obs}}$ value. Adding species to our total model allows reducing the uncertainty in the baselines, so, in general, the $T_{\mathrm{mb}}^{\mathrm{obs}}$ 
I. Haykal et al.: THz spectroscopy and ISM detection of $v_{t}=1$ of ${ }^{13} \mathrm{C}$-methyl formate

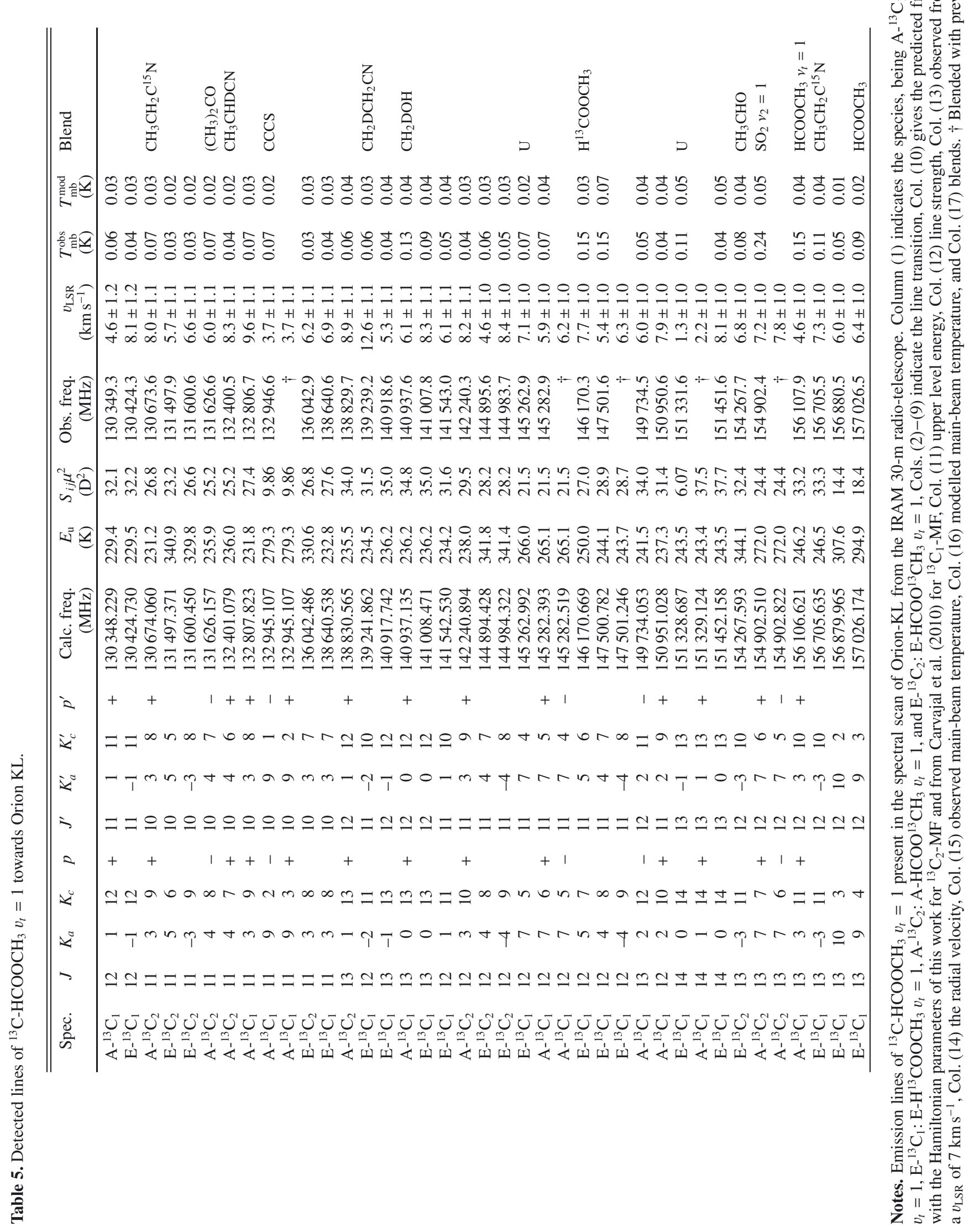

A58, page 7 of 16 


\begin{tabular}{|c|c|c|c|c|}
\hline & 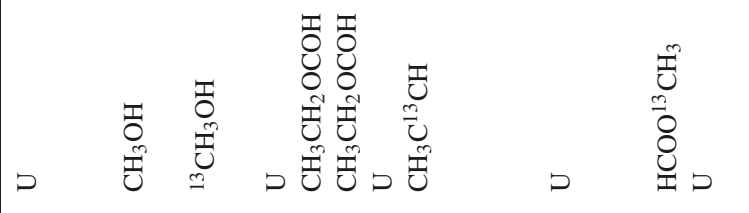 & 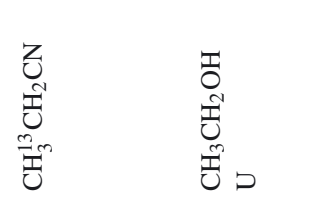 & 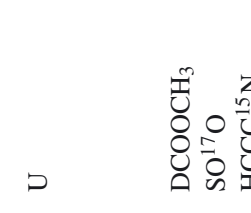 & D \\
\hline & 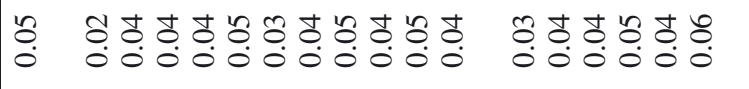 & 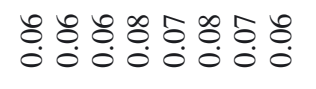 & $\begin{array}{llll}\infty & 0 & 0 & 0 \\
0 & 0 & 0 & 0 \\
0 & 0 & 0 \\
0 & 0 & 0\end{array}$ & 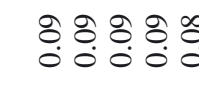 \\
\hline & 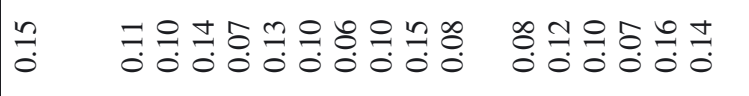 & $\left.\begin{array}{ll}0 & 0 \\
0 & 0\end{array}\right]$ & 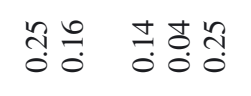 & $\stackrel{0}{\circ} \div \frac{1}{0} \div$ \\
\hline 気 & 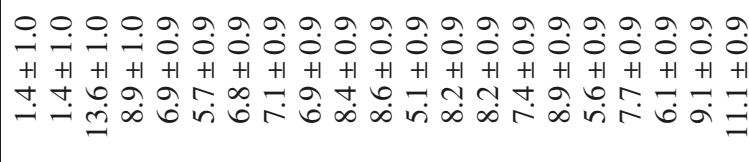 & 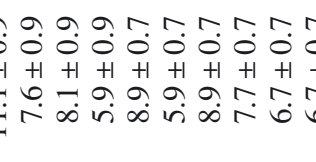 & 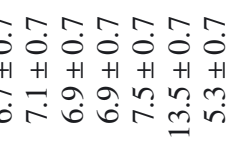 & 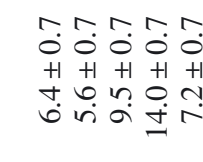 \\
\hline$\sum^{N}$ & 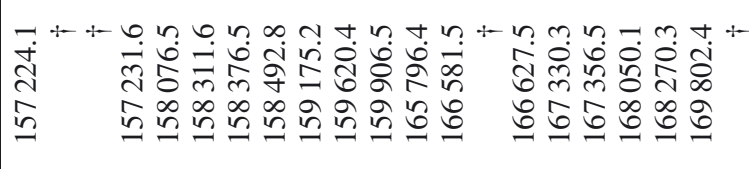 & 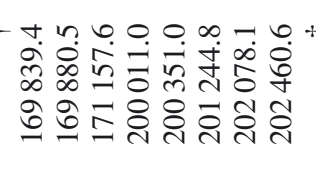 & 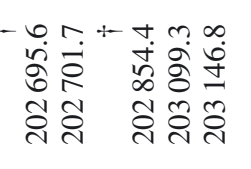 & 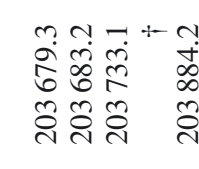 \\
\hline & 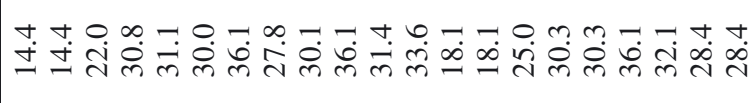 & 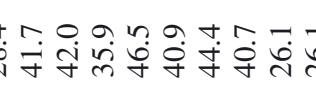 & 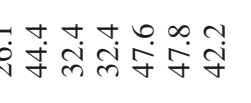 & $\stackrel{0}{\dot{m}} \frac{0}{\sin } \frac{m}{\sin }$ \\
\hline 2 & 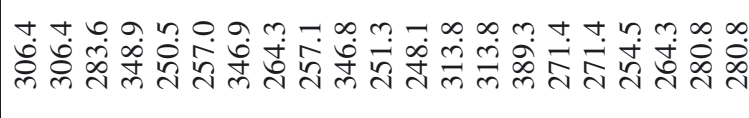 & 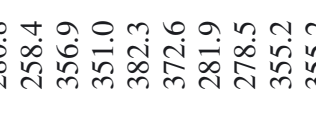 & 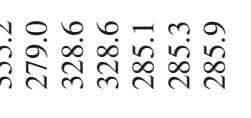 & 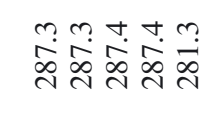 \\
\hline$\sum^{\widehat{N}}$ & 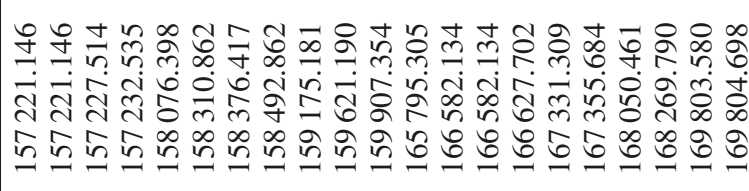 & 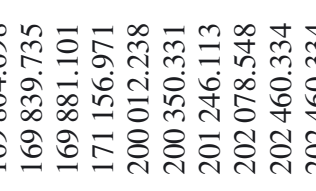 & 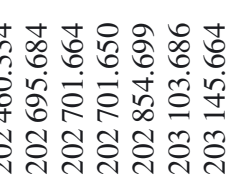 & 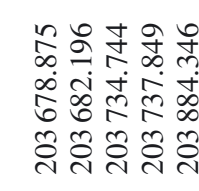 \\
\hline & $+11+1+1$ & ++ & $1+1+1$ & ++ \\
\hline & $m N+a \infty \infty \simeq \wedge$ Ia & $\because \curvearrowleft コ ヒ \simeq \pm コ ヒ$ & $r=r \infty \simeq$ & $\stackrel{\infty}{\sim} \stackrel{\infty}{\sim}$ \\
\hline & 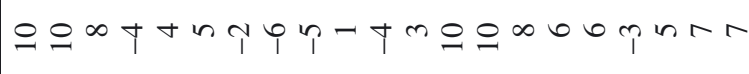 & $-\sigma_{\uparrow} \sim m_{\varphi}+=$ & $E+a a--+$ & $-0 \uparrow 0$ \\
\hline & 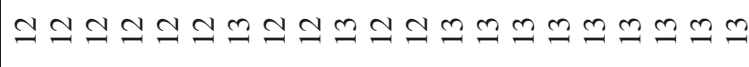 & 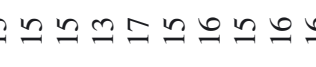 & ゚ே゚゚ニニ゚ & $\stackrel{\infty}{\sim} \stackrel{\infty}{\longrightarrow}$ \\
\hline & $+11+1+1$ & $+\quad++$ & $1+1+1$ & ++ \\
\hline & 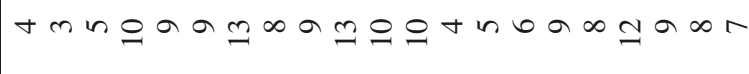 & 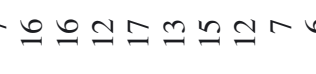 & $0 \simeq \infty \curvearrowleft こ ニ \pm$ & 2929 五 \\
\hline & 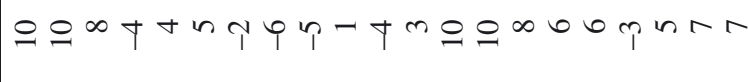 & - & $\exists+a \sigma-r$ & $-0 \uparrow 0$ \\
\hline & 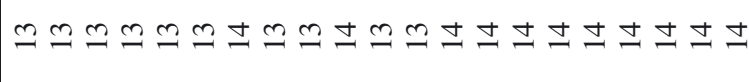 & & & 29 \\
\hline & $U_{n}^{u}$ & & & 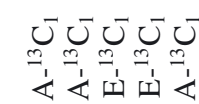 \\
\hline
\end{tabular}




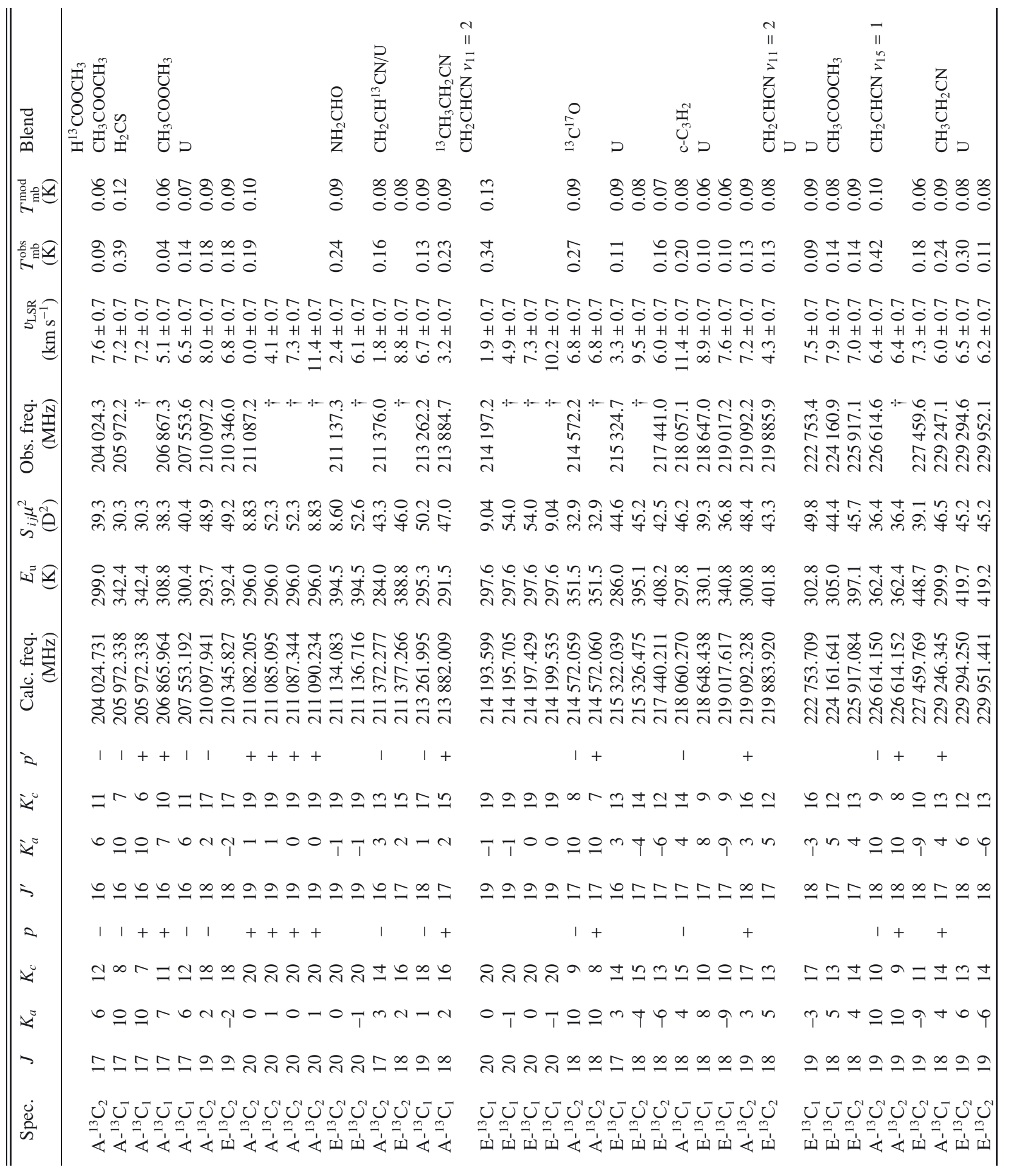




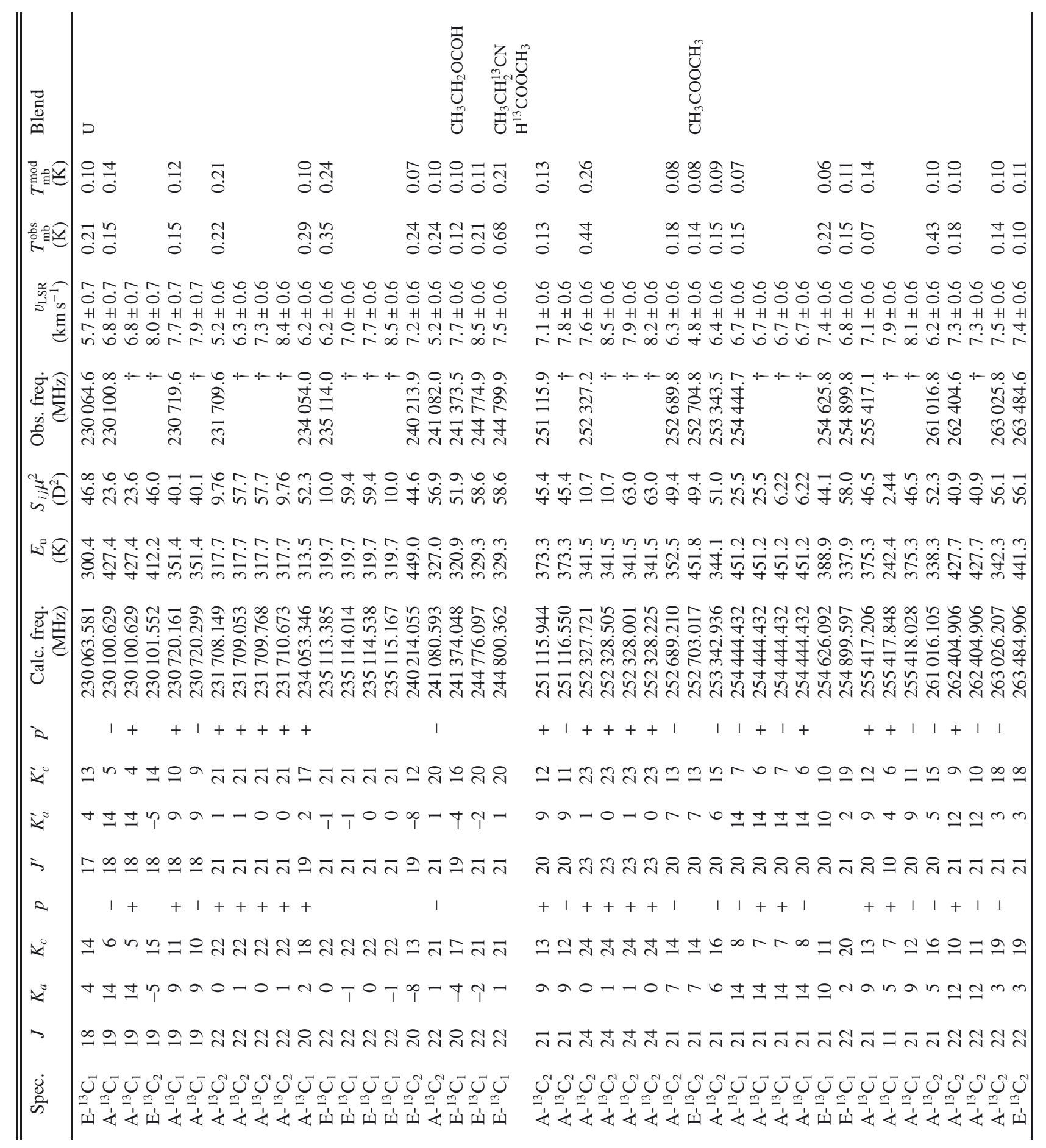




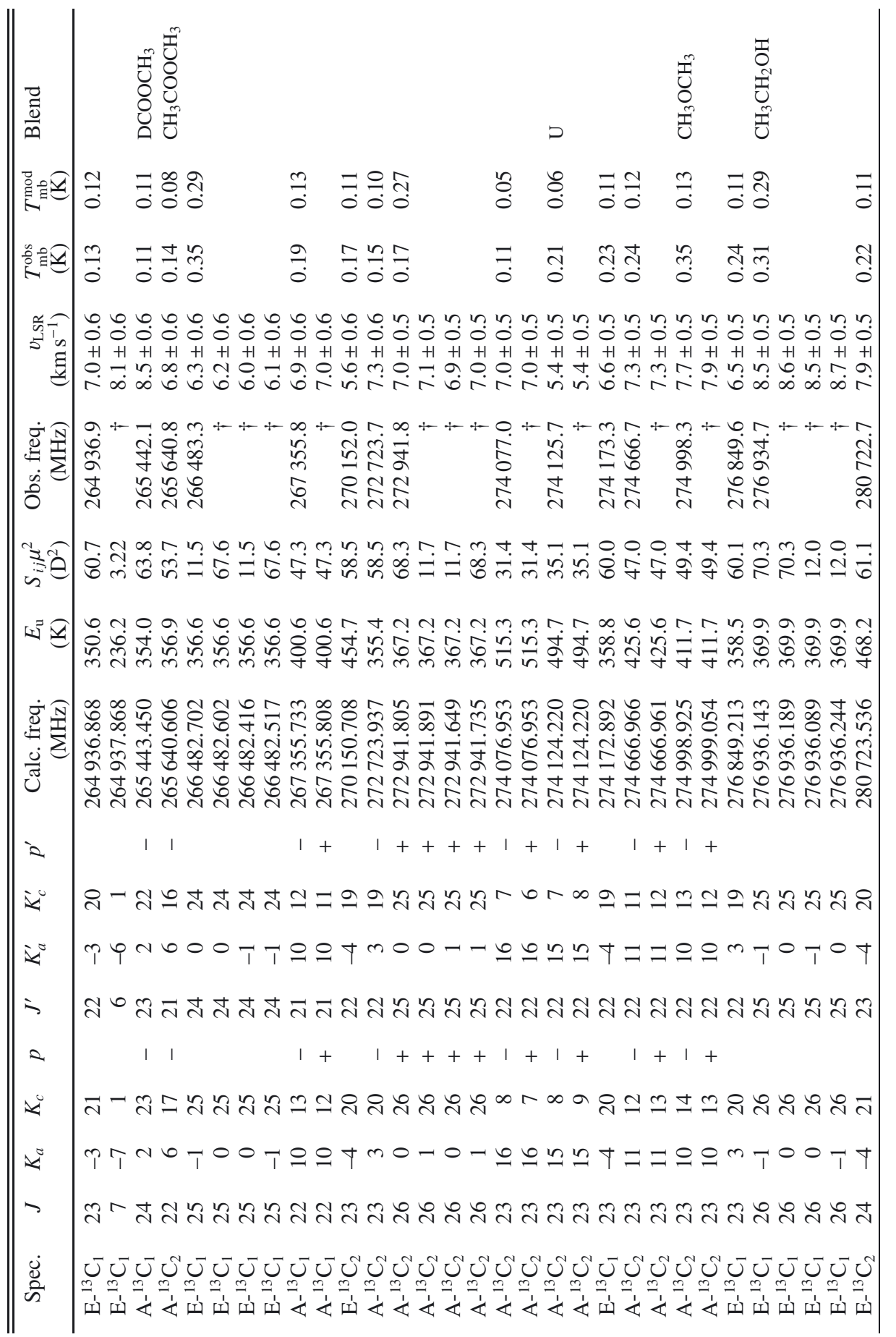



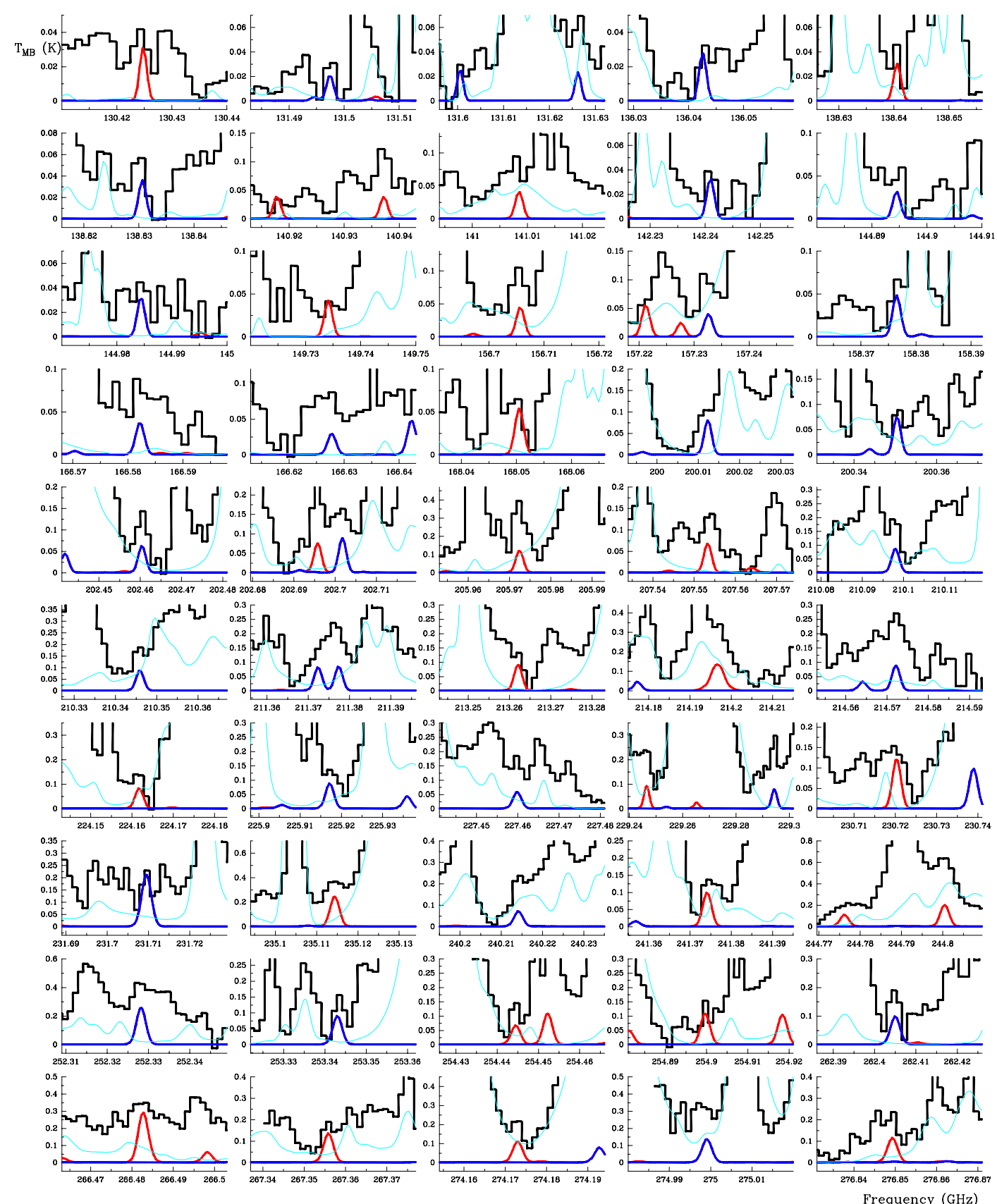

Fig. 2. Selected lines of $\mathrm{A} / \mathrm{E}-\mathrm{H}^{13} \mathrm{COOCH}_{3} v_{t}=1$ (modelled in red) and $\mathrm{A} / \mathrm{E}-\mathrm{HCOO}{ }^{13} \mathrm{CH}_{3} v_{t}=1$ (modelled in dark blue) toward Orion-IRc2. The continuous cyan line corresponds to all lines already modelled in our previous papers except $\mathrm{H}^{13} \mathrm{COOCH}_{3}$ and $\mathrm{HCOO}^{13} \mathrm{CH}_{3} v_{t}=1$ (see Sect. 5.1). A $v_{\text {LSR }}$ of $7 \mathrm{~km} \mathrm{~s}^{-1}$ is assumed.

has to be considered as the total intensity of the detected feature and an upper limit for the intensity of the methyl formate species in this study. Nevertheless, in Table 5 we found some values of the $T_{\mathrm{mb}}^{\mathrm{obs}}$ lower than those predicted by the model (synthetic spectrum $\mathrm{HCOO}^{13} \mathrm{CH}_{3}$ and $\left.\mathrm{H}^{13} \mathrm{COOCH}_{3} v_{t}=1\right)$; uncertainties in the removed baselines are the most probable source for these discrepancies. The uncertainty in the radial velocity was adopted from the spectral resolution of our data. Most unblended detected lines show a radial velocity of $\simeq 7 \mathrm{~km} \mathrm{~s}^{-1}$, in agreement with the expected velocity for emission from the compact ridge component where organic saturated O-rich molecules have the largest abundances inside the region. In addition, most detected lines of methyl formate, its isotopologues, and its first vibrationally excited state appear at the same radial velocity (see e.g.
Carvajal et al. 2009; Margulès et al. 2010; Favre et al. 2011; Tercero et al. 2012; López et al., in prep.).

\subsection{Modelling the data}

To model the emission of $\mathrm{H}^{13} \mathrm{COOCH}_{3}$ and $\mathrm{HCOO}^{13} \mathrm{CH}_{3}$ $v_{t}=1$ we used an excitation and radiative transfer code: MADEX (Cernicharo 2012). This time we applied LTE conditions because we lacked collisional rates for these species. Two compact ridge components $\left(v_{\mathrm{LSR}}=7 \mathrm{~km} \mathrm{~s}^{-1}\right.$ and $\left.\Delta v=3 \mathrm{~km} \mathrm{~s}^{-1}\right)$ are enough to model the line profiles: one at $110 \mathrm{~K}$, with diameter of $15^{\prime \prime}$, and a column density of $(6 \pm 3) \times 10^{13} \mathrm{~cm}^{-2}$ for each state (A and $\mathrm{E}$ ) of each isotopologue, and a hotter and inner compact ridge at $250 \mathrm{~K}$ with a diameter of $10^{\prime \prime}$, and a column 


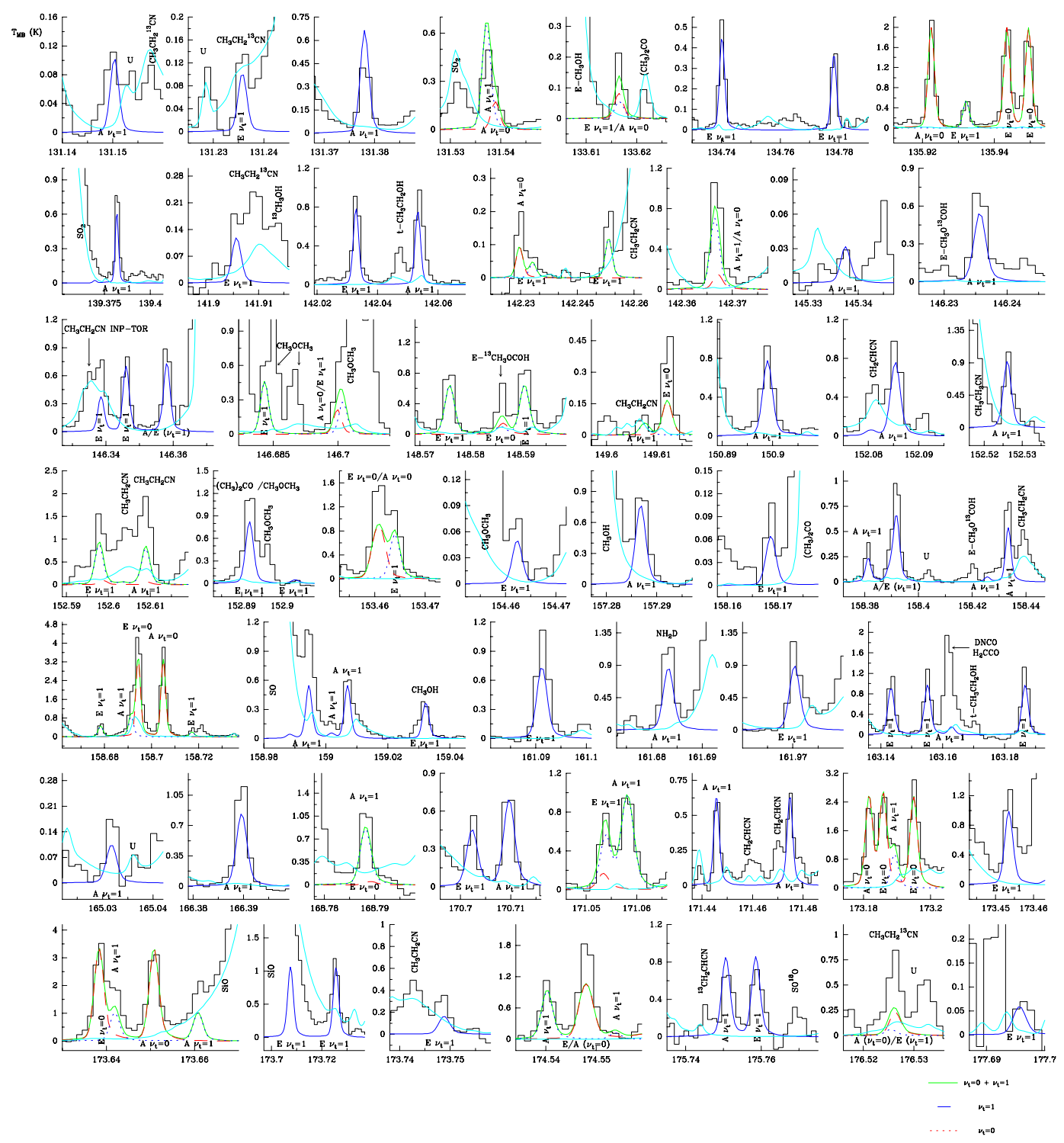

Fig. 3. Selected lines of A/E-HCOOCH $3 v_{t}=1$ (modelled in dark blue) toward Orion-IRc2. The dashed red line and the green continuous line correspond to methyl formate in the ground state and the sum of the emission of $v_{t}=1$ and $v_{t}=0$, respectively. The continuous cyan line corresponds to all lines already modelled in our previous papers except $\mathrm{HCOOCH}_{3} v_{t}=0,1$ (see Sect. 5.1). A $v_{\mathrm{LSR}}$ of $9 \mathrm{~km} \mathrm{~s}^{-1}$ is assumed. The $x$-axis is the frequency in GHz.

density of $(6 \pm 3) \times 10^{14} \mathrm{~cm}^{-2}$ for each state (A and E) of each isotopologue (both components are $7^{\prime \prime}$ offset from the pointing position; interferometric maps show this component offset $\simeq 7$ " southwest from the source $I$ - located $0.5^{\prime \prime}$ south of IRc2, Menten \& Reid 1995; see e.g. Neill et al. 2013 for ALMA cycle 0 maps). The beam dilution for each line (depending on the frequency) has been also taken into account in the calculation of the emerging line intensities. The obtained synthetic spectra is shown in Fig. 2. We obtained source averaged-column densities over the source size given for each component. Uncertainties of the column density results were estimated to be between 20-30\% for this line survey (see Tercero et al. 2010) taking into account errors introduced by different sources, such as the spatial overlap of the different cloud components, the modest angular resolution, or pointing errors. Nevertheless, high overlap problems add another source of uncertainty (rising to 50\%) for results obtained by means of weak lines such as those of $\mathrm{H}^{13} \mathrm{COOCH}_{3}$ and $\mathrm{HCOO}^{13} \mathrm{CH}_{3} v_{t}=1$. All together we obtained a total column density of $(1.4 \pm 0.7) \times 10^{15} \mathrm{~cm}^{-2}$ for each ${ }^{13} \mathrm{C}$ isotopologue of vibrationally excited methyl formate.

\subsubsection{Isotope ratios}

To obtain the ${ }^{12} \mathrm{C} /{ }^{13} \mathrm{C}$ ratio, we included our model for $\mathrm{A} / \mathrm{E}$ $\mathrm{HCOOCH}_{3} v_{t}=1$ (López et al., in prep.). Figure 3 shows selected lines of methyl formate in its first vibrationally excited state in the $2 \mathrm{~mm}$ window (from 130 to $178 \mathrm{GHz}$ ). We modelled these species assuming all components listed in Table 4 and the hotter and inner compact ridge described above. The differences between the considered components with respect to the model of the ${ }^{13} \mathrm{C}$ isotopologues arise because the much more stronger lines of the main isotopologue in all the spectral band (from 80 to $280 \mathrm{GHz}$ ) allow us to distinguish the contribution of several cloud components in the line profiles, although some of them, such as the plateau contribution, are very low. For 
$\mathrm{HCOOCH}_{3} v_{t}=1$ we obtained a total column density of $(1.9 \pm 0.6) \times 10^{16} \mathrm{~cm}^{-2}$.

The column density ratio between the two vibrationally excited isotopologues (main and ${ }^{13} \mathrm{C}$ ) of methyl formate yields a ${ }^{12} \mathrm{C} /{ }^{13} \mathrm{C}$ ratio between $6-35$ (considering the error bars and assuming the same partition function for both species). Taking into account the weakness of the ${ }^{13} \mathrm{C}$ lines, the derived ratios are compatible with the value of ${ }^{12} \mathrm{C} /{ }^{13} \mathrm{C} \simeq 35$ obtained with the column density ratios between ${ }^{13} \mathrm{C}-\mathrm{HCOOCH}_{3}$ and $\mathrm{HCOOCH}_{3}$ in the ground state (see Carvajal et al. 2009; Margulès et al. 2010) and agrees quite well with previous results of this ratio in Orion KL (Johansson et al. 1984; Blake et al. 1987; Demyk et al. 2007; Tercero et al. 2010; Daly et al. 2013; Esplugues et al. 2013b).

\subsubsection{Vibrational temperatures}

We can estimate vibrational temperatures from

$\frac{\exp \left(-\frac{E_{v_{t}=1}}{T_{\mathrm{vib}}}\right)}{f_{v}}=\frac{N\left({ }^{13} \mathrm{C}-\mathrm{HCOOCH}_{3} \quad v_{t}=1\right)}{N\left({ }^{13} \mathrm{C}-\mathrm{HCOOCH}_{3}\right)}$,

where $E_{v_{t}=1}$ is the energy of the vibrational state $(187.6 \mathrm{~K})$, $T_{\text {vib }}$ is the vibrational temperature, $f_{v}$ is the vibrational partition function, $N\left({ }^{13} \mathrm{C}-\mathrm{HCOOCH}{ }_{3} v_{t}=1\right)$ is the column density of the vibrational state, and $N\left({ }^{13} \mathrm{C}-\mathrm{HCOOCH}_{3}\right)$ is the total column density of ${ }^{13} \mathrm{C}$ methyl formate. Taking into account that $N\left({ }^{13} \mathrm{C}-\mathrm{HCOOCH}_{3}\right)=N($ ground $) \times f_{v}$ and assuming the same partition function for these species in the ground- and the first vibrationally excited states, we only need the energy of the vibrational state and the column densities of ${ }^{13} \mathrm{C}-\mathrm{HCOOCH}_{3}$ $v_{t}=1$ and ${ }^{13} \mathrm{C}-\mathrm{HCOOCH}_{3} \quad v_{t}=0$ to derive the vibrational temperatures.

In Carvajal et al. (2009) we did not consider the hotter component of the compact ridge for column density calculations. After several works on methyl formate (Carvajal et al. 2009; Margulès et al. 2010; Tercero et al. 2012; Coudert et al. 2013; López et al., in prep.) we realize that this hotter component plays an important role in the global analysis of this molecule. In Margulès et al. (2010) we introduced a hot compact ridge to model the lines of main isotopologue of the methyl formate to properly reproduce the line profiles. After that, the study of the vibrationally excited states (this work and A. López et al., in prep.) confirms that a hot compact ridge is needed to understand the emission of this molecule. Therefore, quite strong lines such as those of ${ }^{13} \mathrm{C}-\mathrm{HCOOCH}_{3}$ require the hot compact ridge component to obtain the best fit. Consequently, here we again modeled the emission from $\mathrm{H}^{13} \mathrm{COOCH}_{3}$ and $\mathrm{HCOO}^{13} \mathrm{CH}_{3}$ taking into account a compact ridge at a temperature of $250 \mathrm{~K}$ and a source size of 10". As in Carvajal et al. (2009), all cloud components of Table 4 where taken into account to reproduce the line profiles. Using MADEX and assuming LTE conditions, the obtained column densities for each ${ }^{13} \mathrm{C}$ isotopologue and each state $(\mathrm{A}$ and $\mathrm{E})$ are $(2.0 \pm 0.6) \times 10^{15} \mathrm{~cm}^{-2}$ and $(2.0 \pm 0.6) \times 10^{14} \mathrm{~cm}^{-2}$ for the $T=250 \mathrm{~K}$ compact ridge and the $T=110 \mathrm{~K}$ compact ridge, respectively, and $(1.0 \pm 0.3) \times 10^{13} \mathrm{~cm}^{-2}$ for the plateau, the extended ridge, and the hot core. These values yield a total column density of a factor 3 higher than obtained in Carvajal et al. (2009). This difference is mostly due to the reduced source size when we introduced the hotter component of the compact ridge.

At this point, we were ready to derive the vibrational temperatures. We assumed that both gases (ground-state and vibrationally excited) are spatially coincident, so the calculated vibrational temperatures have to be considered as lower limits. A
$T_{\text {vib }}=156 \mathrm{~K}$ was obtained for $\mathrm{H}^{13} \mathrm{COOCH}_{3}$ and $\mathrm{HCOO}^{13} \mathrm{CH}_{3}$ $v_{t}=1$ in each compact ridge component. This value is similar to the averaged kinetic temperature we adopted in this model $(180 \mathrm{~K})$. This result indicates that collisions are probably the main mechanism to populate the vibrationally excited levels of methyl formate.

\section{Conclusion}

We measured the spectra of $\mathrm{HCOO}^{13} \mathrm{CH}_{3}$ from 75 to $940 \mathrm{GHz}$. We analyzed 2881 lines from the first excited torsional states, 5728 new lines corresponding to the ground-vibrational states were also measured and added to the previous ones from Carvajal et al. (2009). The global fit of the 9455 lines, taking into account the internal rotation motion, was made using the rhoaxis-method and the BELGI code. Fifty-two parameters could be determined, the global fit of both states permitted us to obtain uncorrelated values of the torsional parameters: $F, V_{3}$, and $V_{6}$. The value of barrier height $\left(V_{3}=369.93168(395) \mathrm{cm}^{-1}\right)$ has been significantly improved.

Owing to this work and Carvajal et al. (2009), accurate predictions of line positions and intensities were performed. In the line survey of Orion-KL with the IRAM 30 m telescope, this permits detecting 135 spectral features in the range $80-280 \mathrm{GHz}$; there are no missing transitions in this range. This is the first detection of an excited vibrational state of a methyl formate isotopologue.

At the beginning of the line identification process of this line survey (in 2005), nearly 8000 spectral features were U lines. In 2007 we began a close collaboration between astronomers and spectroscopists to reduce the uncertainty due to unidentified lines in spectral surveys. New isotopologues of ethyl cyanide and methyl formate (Demyk et al. 2007; Margulès et al. 2009, 2010; Carvajal et al. 2009; Tercero et al. 2012; Coudert et al. 2013) and new vibrationally excited states of formamide (Motiyenko et al. 2012), ethyl cyanide (Daly et al. 2013), and vinyl cyanide (López et al. 2014) have been studied in spectroscopy laboratories and detected in Orion KL for the first time space. Altogether, we reduced 3000 of unidentified lines through these studies. At this point, we were ready to search for new molecular species, detecting methyl acetate and gauche-ethyl formate (Tercero et al. 2013) and gauche-ethyl mercaptan (Kolesniková et al. 2014) for the first time in space, and providing the tentative detection of phenol (Kolesniková et al. 2013). These new species together with the work of López et al. (in prep., about vibrationally excited $\mathrm{CH}_{3} \mathrm{OCOH}$ and $\mathrm{CH}_{3} \mathrm{COOH}$ ) account for $\simeq 1000$ lines. Up to date, we have reduced 4000 of $\mathrm{U}$ lines in the survey of Orion KL. We expect that a large number of the still unidentified lines arise from vibrationally modes of abundant species. However, low-lying vibrationally excited states of abundant molecules such as ethyl cyanide (for example the $v_{13}=2 / v_{21}=2$ state at $\sim 420 \mathrm{~cm}^{-1}$ ) or methanol are still only poorly characterized in the laboratory, and certainly contribute to the remaining U-lines. The main goal of our studies is to provide the community with a fully analysed line survey of Orion that will constitute a template for ALMA observations of warm clouds.

Acknowledgements. M.C. acknowledges the financial support the Spanish Government through grant FIS2011-28738-C02-02, and by a joint project within the framework of a CNRS (France) and CSIC (Spain) agreement (Code No.: 2011 FR0018). J.C., A.L. and B.T. thank the Spanish MINECO for funding support from grants CSD2009-00038, AYA2009-07304, and AYA2012-32032. This work was supported by the Centre National d'Etudes Spatiales (CNES) and the Action sur Projets de l'INSU, "Physique et Chimie du Milieu Interstellaire". This work was also performed under the ANR-08-BLAN-0054. 
I. Haykal et al.: THz spectroscopy and ISM detection of $v_{t}=1$ of ${ }^{13} \mathrm{C}$-methyl formate

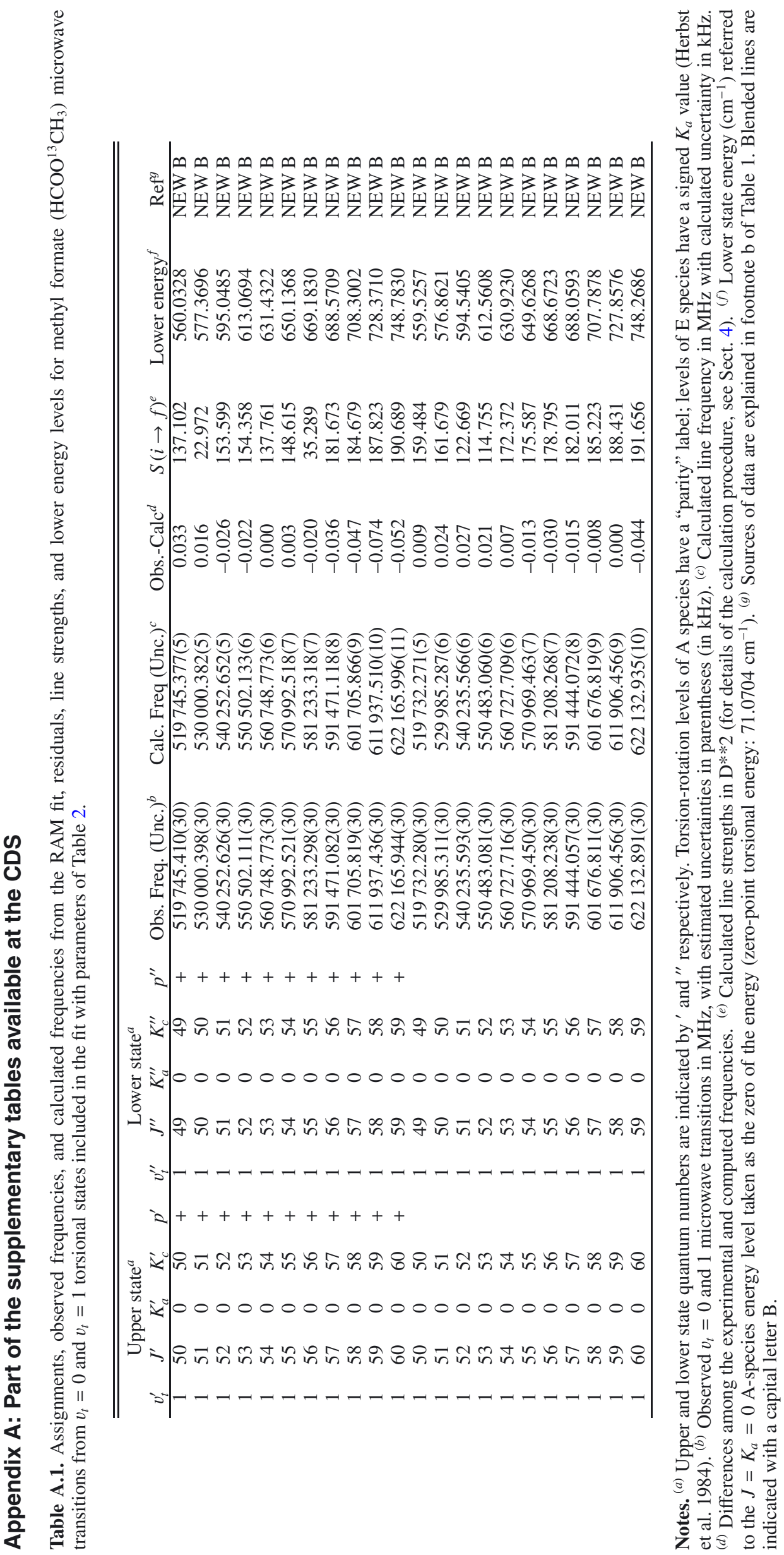




\section{References}

Bell, T. A., Cernicharo, J., Viti, S., et al. 2014, A\&A, 564, A114 Blake, G. A., Sutton, E. C., Masson, C. R., \& Philips, T. H. 1987, ApJ, 315, 621 Brown, R. D., Crofts, J. G., Gardner, F. F., et al. 1975, ApJ, 197, L29 Churchwell, E., \& Winnewisser, G. 1975, A\&A, 45, 229

Carvajal, M., Willaert, F., Demaison, J., \& Kleiner, I. 2007, J. Mol. Spectrosc., 246,158

Carvajal, M., Margulès, L., Tercero, B., et al. 2009, A\&A, 500, 1109

Carvajal, M., Kleiner, I., \& Demaison, J. 2010, ApJS, 190, 315

Cernicharo 1985, Internal IRAM report (Granada: IRAM)

Cernicharo, J. 2012, in ECLA-2011: Proc. of the European Conf. Laboratory

Astrophysics, EAS Publ. Ser., eds C. Stehl, C. Joblin, \& L. d'Hendecourt

(Cambridge: Cambridge Univ. Press), 251

Cernicharo, J., Tercero, B., Fuente, A., et al. 2013, ApJ, 771, L10

Comito, C., Schilke, P., Phillips, T. G., et al. 2005, ApJS, 156, 127

Coudert, L. H., Drouin, B. J., Tercero, B., et al. 2013, ApJ, submitted

Curl, R. F. 1959, J. Chem. Phys., 30, 1529

Daly, A. M., Bermúdez, C., López, A., et al. 2013, ApJ, 768, 81

Demyk, K., Mäder, H., Tercero, B., et al. 2007, A\&A, 466, 255

Demyk, K., Wlodarczak, G., \& Carvajal, M. 2008, A\&A, 489, 589

Esplugues, G. B., Tercero, B., Cernicharo, J. et al. 2013, A\&A, 556, A143

Esplugues, G. B., Cernicharo, J., Viti, S., et al. 2013, A\&A, 559, A51

Favre, C., Despois, D., Brouillet, N., et al. 2011, A\&A, 532, A32

Favre, C., Carvajal, M., Field, D., et al. 2014, ApJ, submitted

Groner, P. 1997, J. Chem. Phys., 107, 4483

Groner, P. 2012, J. Mol. Spectrosc., 278, 52

Haykal, I., Motiyenko, R. A., Margulès, L., \& Huet, T. R. 2013a, A\&A, 549, A96

Haykal, I., Margulès, L., Motiyenko, R. A., et al. 2013b, ApJ, 777, 120

Herbst, E., Messer, J. K., De Lucia, F. C., \& Helminger, P. 1984, J. Mol. Spectrosc., 108, 42

Hougen, J. T., Kleiner, I., \& Godefroid, M. 1994, J. Mol. Spectrosc., 163, 559

Ilyushin, V., Alekseev, E. A., Dyubko, S. F., \& Kleiner, I. 2003, J. Mol. Spectrosc., 220, 170

Ilyushin, V., Kleiner, I., \& Lovas, F. J. 2008, J. Phys. Chem. Ref. Data, 37, 97 Ilyushin, V. V., Kryvda, A., \& Alekseev, E. 2009, J. Mol. Spectrosc., 255, 32

Johansson, L. E. B., Andersson, C., Elldér, J., et al. 1984, A\&A, 130, 227

Kirtman, B. 1962, J. Chem. Phys., 37, 2516

Kleiner, I. 2010, J. Mol. Spectrosc., 260, 1
Kleiner, I., Hougen, J. T., Grabow, J. U., et al. 1996, J. Mol. Spectrosc., 179, 41

Kobayashi, K., Ogata, K., Tsunekawa, S., \& Takano, S. 2007, ApJ, 657, L17

Kolesniková, L., Daly, A. M., Alonso, J. L., Tercero, B., \& Cernicharo, J. 2013, J. Mol. Spectrosc., 289, 13

Kolesniková, L., Tercero, B., \& Cernicharo, J. 2014, ApJ, 784, L7

Lees, R. M., \& Baker, J. G. 1968, J. Chem. Phys., 48, 5299

Lin, C. C., \& Swalen, J. D. 1959, Rev. Mod. Phys., 31, 841

López, A., Tercero, B., Kisiel, Z., et al. 2014, A\&A, submitted

Maeda, A., Medvedev, I. R., De Lucia, F. C., \& Herbst, E. 2008a, ApJS, 175, 138

Maeda, A., De Lucia, F. C., \& Herbst, E. 2008b, J. Mol. Spectrosc., 251, 293

Margulès, L., Motiyenko, R. A., Demyk, K., et al. 2009, A\&A, 493, 565

Margulès, L., Huet, T. R., Demaison, J., et al. 2010, ApJ, 714, 1120

Menten, K. M., \& Reid, M. J. 1995, ApJ, 445, L157

Motiyenko, R. A., Margulès, L., Alekseev, E. A., Guillemin, J.-C., \& Demaison, J. 2010, J. Mol. Spectrosc., 264, 94.

Motiyenko, R. A., Tercero, B., Cernicharo, J., \& Margulès, L. 2012, A\&A, 548, A71

Neill, J. L., Crockett, N. R., Bergin, E. A., Pearson, J. C., \& Xu, L.-H. 2013, ApJ, 777, 85

Oesterling, L. C., Ferguson, D. W., Herbst, E., \& De Lucia, F. C. 1995, J. Mol. Spectrosc., 172, 469

Pardo, J. R., Cernicharo, J., \& Serabyn, E. 2001, IEEE Tras. Antennas and Propagation, 49, 12

Persson, C. M., Olofsson, A. O. H., Koning, N., et al. 2007, A\&A, 476, 807

Schilke, P., Benford, C. J., Hunter, T. R., Lis, D. C., \& Philips, T. G. 2001, ApJS, 132, 281

Tercero, B. 2012, Ph.D., Univ. Complutense de Madrid

Tercero, B., Pardo, J. R., Cernicharo, J. R., \& Goicoechea, J. R. 2010, A\&A, 517, A96

Tercero, B., Vincent, L., Cernicharo, J., Viti, S., \& Marcelino, N. 2011, A\&A, 528, A26

Tercero, B., Margulès, L., Carvajal, M., et al. 2012, A\&A, 538, A119

Tercero, B., Kleiner, I., Cernicharo, J., et al. 2013, ApJ, 770, L13

Tudorie, M., Ilyushin, V., Vander Auwera, J., et al. 2012, J. Chem. Phys., 137, 064304

Willaert, F., Møllendal, H., Alekseev, E., et al. 2006, J. Mol. Struct., 795, 4

Takano, S., Sakai, Y., Kakimoto, S., Sasaki, M., \& Kobayasho, K. 2012, PASJ, 64,89 